\title{
Passos em Falso da Razão Antiimperialista: Bourdieu, Wacquant, e o 0 rfeu e o Poder de $\mathrm{H}$ anchard*
}

John French

\section{Resumo}

O s estudos afro-americanos, assim chamados e praticados nos Estados U nidos, são um instrumento de imperialismo cultural? D iscussões deraça, desigualdade ou opressão racial em outras sociedades, quando conduzidas por norte-americanos, devem ser vistas como "brutais intrusões etnocêntricas"? Estas estão entreastesescentrais deuma vigorosa polêmica de dois sociólogosfranceses, Pierre B ourdieu e L oïc W acquant em um artigo de 1999 intitulado "Sobre as Artimanhas da R azão I mperialista". Como prova, Bourdieu e W acquant chamam a atenção para o recente diálogo acadêmico transnacional sobre a questão racial no Brasil e denunciam a "imposição" de uma "tradição americana", "modelo" e "dicotomia" racial no Brasil. E m particular, el es atacam como um "vene no etnocêntrico" uma monografia de 1994, escrita por M ichael $\mathrm{H}$ anchard, sobre os movimentos brasileiros de consciência negra, $O$ rfeu e o Poder: 0 M ovimento N egro do Rio de Janeiro e São Paulo, Brasil, 1945-1988. 0 presente artigo disseca a caracterização errônea de Bourdieu eW acquant do atual diálogo entre Estados U nidose Brasil a respeito da diáspora africana no $\mathrm{N}$ ovo $\mathrm{M}$ undo. Ele identifica seus principais passos em falso eerros de julgamento eofereceuma crítica do modelo esquemático de circulação intelectual que os autores propõem no artigo. D epois de demonstrar a sua representação radical mente equivocada do O rfeu e o Poder de $\mathrm{M}$ ichael $\mathrm{H}$ anchard, o presente artigo termina com uma discussão a respeito do recenteboom de publicações acadêmicas, es-

\footnotetext{
* Tradução de Fabio D urão.
}

Estudos Afro-Asiáticos, Ano 24, oㅡ 1, 2002, pp. 97-140 
John French

critas tanto por brasileiros quanto por norte-americanos, que abordam questões de raça, cor e nação no Brasil a partir de uma perspectiva da diáspora.

Palavras-chave: antiimperialismo, diálogo Brasil-Estados U nidos, raça, desigualdade racial, opressão racial, Bourdieu, Wacquant, $\mathrm{H}$ anchard

\section{Abstract \\ The M issteps of Anti-imperialism Reason: Bourdieu, Wacquant and $\mathrm{H}$ anchard's $\mathrm{O}$ rpheus and Power}

Are the Afro-American Studies - as called and practiced in the USA - an instrument of the cultural imperialism? Is it possible to consider race discussion, racial inequality or repression in other societies as a "brutal ethnocentric interference" when undertaken by $\mathrm{N}$ orth-Americans? The present article deeply analyses the mistaken characterization of Bourdieu and Wacquant about the present dialogue between U nited States and Brazil, related to the African diaspore in the $\mathrm{N}$ ew W orld. Besides, it points out their main missteps and misjudges. It also offers a critique of the schematic mode of intellectual circulation that those authors showed in their article " $O \mathrm{n}$ the Cunning of Imperialist Reason". After demonstrating their strongly mistaken representation of $\mathrm{M}$ ichael $\mathrm{H}$ anchard's 0 rpheus and Power, the present article finishes with a discussion concerning the recent boom of academic publications, written either by B razilians or $\mathrm{N}$ orth-Americans on race, color and nation in Brazil towards a diasporic perspective.

Keywords: anti-imperialism, Brazil/U SA dialogue, race, Bourdieu, Wacquant, $\mathrm{H}$ anchard.

\section{Résumé}

Faux Pas de la Raison Anti-impérialiste: Bourdieu, Wacquant et O rfeu e o Poder de $\mathrm{H}$ anchard

Les études afro-américaines, ainsi dénommées et pratiquées aux États-U nis, seraient-elles un instrument d'impérialisme culturel? Les débats sur les races, les inégalités ou l'oppression raciale dans d'autres sociétés, lorsqu'ils proviennent de $\mathrm{N}$ ord-américains, doivent-ils être considérés comme des "brutales intrusions ethnocentriques"? Ces questions se trouvent dans la forte polémique déclenchée par deux sociologuesfrançais, PierreB ourdieu et Loïc W acquant, dansleur article

\section{8}


de 1999 "Sur les Ruses e la Raison Impérialiste". Ces auteurs y invoquent le récent dialogue transnational sur la question raciale au Brésil tout en dénonçant "la contrainte" d'une "tradition américaine", "modèle" et "dichotomie" raciale au Brésil. Ils s'attaquent, en particulier, à une monographie - qu'ils considèrent comme un "poison ethnocentrique" - écrite en 1994 par Michael $\mathrm{H}$ anchard sur les mouvements brésiliens sur la question noire Orfeu e o Poder: 0 movimento negro do Rio de Janei ro e São Paulo, Braśl, 1945-1988. O n décortique ici la conception erronée que Bourdieu et $W$ acquant présentent sur l'actuel dialogueB résil-États-U nis au sujet dela diaspora africaine dans le $\mathrm{N}$ ouveau M onde. $\mathrm{O} n$ cherche à identifier leurs principaux faux pas et erreurs de jugement, tout en critiquant le modèle trop schématique de la circulation intellectuelle proposée par les deux auteurs. A près avoir montré leur vision tout à fait fausse de l'article de $\mathrm{H}$ anchard, on présente une discussion sur le récent foisonnement de publications chez des auteurs aussi bien brésiliens que nord-américains touchant les questions de race, couleur de peau et nation au Brésil, d'après une perspective de la diaspora.

M ots-clé: anti-impérialisme, dialogue Brésil-États-U nis, race, inégalité raciale, oppression raciale, Pierre Bourdieu, Loïc Wacquant, M ichael $\mathrm{H}$ anchard 
$S_{\text {ão os estudos afro-americanos, como definidos e praticados }}$ ral dos EU A? D evem as discussões de raça, desigualdade racial, ou opressão racial em outras sociedades, quando conduzidas por norte-americanos, serem vistas como "intrusões etnográficas brutais"? São os termos "raça" e "racismo" conceitos perniciosos "que os EU A exportam eimpõem" aos países "dominados" pelo imperialismo cultural americano? E devem os estudos abertamente anti-racistas, levados a cabo nos EU A sobre outros países, serem vistos como prova da infiltração de "perspectivas racistóides" norte-americanas em todos camposintelectuais nacionais? Estas estão entre as tesescentrais seuma vigorosa polêmica ocorrida em 1998 e protagonizada por dois sociólogos franceses, Pierre Bourdieu e Loïc W acquant, em um artigo traduzido para o inglês em 1999 com o título "Sobre as Artimanhas da Razão Imperialista" (Bourdieu \& W acquant, 1999:44, 46, 48). ${ }^{1}$

Como prova, Bourdieu eW acquant chamam a atenção para o recente diálogo acadêmico transnacional acerca da raça no Brasil, o país no hemisfério ocidental com a maior populaçã̃o de descendentes de africanos. Eles denunciam a "imposição" de uma "tradição americana[sic]", " "modelo" e "dicotomia deraça" ao Brasil, através da pesquisa levada a cabo "por [norte-] americanos elatino-americanos formados nos EU A" (ibidem:44). M ais amplamente, sugerem que as recentes publicações lidando com raça, desigualdade racial, e mobilização racial no Brasil representam a transposição de um problema estrangeiro (dos EUA) para uma sociedadeem quea noção de "raça" não faz sentido. Para estes estudiosos franceses - nenhum dos dois especialistas em Brasil - as comparações entre as realidades brasileira e norte-americana em termos de suas diásporas é, por definição, uma "intrusão etnocêntrica" por parte da nação mais poderosa. Em particular, atacam como um "veneno etnocêntrico" uma monografia de 1994, escrita por $\mathrm{M}$ ichael $\mathrm{H}$ anchard a respeito dos movimentos brasileiros de 
John French

"consciência negra", 0 rfeu eo Poder: 0 M ovimento N egro do Rio de Janeiro eSão Paulo, Brasil, 1945-1988 (ibidem; H anchard, 1994a).

Como um historiador com vinteanos de pesquisa no e sobre - Brasil, pretendo dissecar a caracterização errônea de Bourdieu e W acquant do presente diálogo entre EU A e Brasil acerca da diáspora africana no $\mathrm{N}$ ovo $\mathrm{M}$ undo. Ainda que tenha simpatia pela retórica antiimperialista destes autores, identificarei passos em falso fundamentais e erros de julgamento que comprometem o projeto intelectual e político que pretendem defender. D epois de caracterizar brevemente seu modelo esquemático de circulação intelectual transnacional, apresentarei sua representação radical mente equivocada de $\mathrm{O}$ rfeu e 0 Poder de $\mathrm{M}$ ichael $\mathrm{H}$ anchard, e situarei a contribuição deste último dentro da literatura mais ampla sobrea dinâmica de raça e cor no Brasil. Terminarei com uma breve discussão a respeito do atual boom das publicações acadêmicas, escritas tanto por brasileiros quanto norte-americanos, que abordam questões da raça, cor e nação no Brasil dentro de uma perspectiva mais ampla da diáspora no $\mathrm{N}$ ovo M undo.

\section{C irculação Intelectual, a "M cdonaldização do Pensamento" e Raça}

Ao evitar eufemismos, Bourdieu eW acquant quebraram um tabu contemporâneo contra a menção aberta do imperial ismo dos EU A e suas manifestações ideológicas que se seguem a ele. R ejeitam devidamente o termo globalização, que "tem o efeito, se não a função, de fazer submergir os efeitos do imperialismo em um ecumenismo cultural, ou fatalismo econômico, e de fazer as relações transnacionais de poder parecerem uma neutra necessidade". Esta "crença [norte] americanocêntrica na 'globalização'", continuam, é "compreendida, pura esimplesmente como a [norte-] americanização do mundo ocidental e [...] do universo inteiro". A habilidade dos arquitetos da globalização de evitar a investigação ea crítica intelectuais sérias - sugerem - não deixa deforma al guma deser relacionada ao "remodelamento das relações sociais e práticas culturais nas sociedades avançadas de acordo com o padrão dos EU A" queé "hoje em dia aceito com resignação," senão com "um entusiasmo envergonhado" (Bourdieu e W acquant, 1999:42,46, 43).

Em seu tom maiscuidadoso, Bourdieu eW acquant criticam a "difusão do 'pensamento dos EU A' nas ciências sociais" e, mais particularmente, "a hegemonia da produção dos EU A" no merca-

\section{2}


Passosem Falso da Razão Antiimperialista...

do intelectual mundial. Em seu tom mais histérico, descrevem a exportação de idéias e conceitos, "freqüentemente corrompidose apagados", como a "mcdonaldização proliferante do pensamento". A "doxa intelectual com pretensões planetárias" dos Estados U nidos está se tornando rapidamente "o lugar-comum da grande nova vulgata global, que uma repetição infinita na mídia paulatinamente transforma em bom senso universal". M aterial izadas em uma série de termos "indefinidos evagos" estas tendências nocivas são exprimidas "em um jargão extraordinário, umaterrível (eaterrorizante) língua franca internacional", que tem crescentemente "atravessado o Atlântico em plena luz do dia ou... tem sido contrabandeada". D esta maneira, "as noções do senso comum acadêmico [norte] americano [chegaram] a penetrar" o campo intelectual de países-alvo na forma "insidiosa" de "termos isolados aparentemente técnicos" que funcionam "como verdadeiros motes e palavras políticas codificadas" (entre os exemplos dados estão tais ortodoxias neoliberais como "flexibilidade do trabalho", "guetificação" e "subclasse urbana"). Estas tendências do pensamento americano - os autores notam de forma acertada - são marcadas pela negação da idéia de classe e por "um tipo de despolitização, por princípio, de problemas sociais e políticos", que ficam "desprovidos de qualquer referência a qualquer tipo de dominação" (ibidem: 50, 52, 46, 47, 52, 42, 53-4, 54, 43, 42, 49).

N o entanto, a apressada descrição oferecida por Bourdieu e W acquant os deixa com uma questão não resolvida: como devemos explicar "a extraordinária força da imposição" do "imperialismo cultural dosEU A?" C omo uma resposta parcial, citam o "papel fundamental exercido pelas mais importantes fundações filantrópicas e de pesquisa americanas" ea "internacionalização das publicações acadêmicas". Todavia, admitem que esses fatores, mesmo quando "somados [,] não podem explicar de forma completa a hegemonia da produção dos EUA" no "mercado intelectual mundial". Ao explicar a predominância dos EU A, Bourdieu e Wacquant selecionam colaboradores não-norte-americanos para sua crítica: aqueles "passeurs semi-acadêmicos, 'carreiristas' e importadores de produtos culturais fajutos ou préfabricados" nos "países-alvo" que são atraídos pel os "Iucros materiais e simbólicos" a serem obtidos de "uma aderência mais ou menos assumida ou envergonhada ao modelo derivado dos Estados U nidos" (idem:54, 46-7).

A dinâmica da exportação intelectual do imperialismo dos EU A - argumentam Bourdieu eW acquant - obedece à mesma ló- 
gica de outros produtos de exportação "da grande indústria cultural [norte] americana como o jazz ou o rap" ou os jeans: eles "devem parte da sedu ção quase universal que exercem sobre os jovens ao fato deserem produzidos e usados por minorias subordinadas". Por analogia, os "falsos universalismos" intelectuais promovidos pelosEU A adquirem um "chamativo de mensagens de libertação" por causa de sua associação com "disci plinas tidas como marginais ou subversivas, tais como os Estudos Culturais, Estudos de M inoria, Estudos G ay, ou Estudos Feministas". D e fato, "'intelectuais progressistas' dos EUA, ou 'intelectuais de cor' no caso de desigualdade racial" desempenham um papel especial, justamente porque "pareceriam estar acima de qual quer suspeita para promover os interesses hegemônicos" dos EU A. D esta forma, "tais mistificadores mistificados [...] transportam sem saber a parteoculta- e freqüentemente maldita - dos produtos culturais [norte-americanos] que são postos em circulação" pelo mundo inteiro (idem:50-1).

Impacientes e excessivamente críticos, Bourdieu e Wacquant sofrem de uma visão afunilada em sua caricatura geral e indiferenciada das tendências intelectuais "americanas" e sua difusão internacional. D emonstram a mais acentuada eimpressionante ceguei ra, intelectual e política, quando descrevem movimentos etendências intelectuais anti-racistas como um exemplo-chavedo imperialismo cultural dos EU A em ação. Em seu ponto de vista, um dos mais perturbadores desd obramentostem sido a habilidade desta "sociodice racial (ou racista)" norte-americana "de se globalizar recentemente", que apresentam como "uma das provas mais marcantes da dominação simbólica exercida pelos EU A sobre qualquer tipo de produção acadêmica ou semi-acadêmica". Para estes intelectuais franceses, os presentes esforços por parte de norte-americanos em abordar questões de opressão racial e étnica no exterior inevitavelmente refletem a tendência geral da "visão de mundo [norte] americana [...] de se impor como um ponto de vista universal, especialmente quando se depara com questões como de 'raça'" (idem: 45-6)

Para Bourdieu eW acquant, 0 apelo internacional deste discurso racial dos Estados U nidos advém, em grande parte, do seu anti-racismo ostensivo; na realidade, os autores misturam discursos norte-americanos, tanto racistas quanto anti-racistas, e apresentam o processo como "a quase universalização do conceito popularizado de 'raça' nos EU A, como um resultado da exportação pelo mundo inteiro de categorias acadêmicas dos Estados U ni-

\section{4}


Passosem Falso da Razão Antiimperialista...

dos". "'T eorias' de'relações raciais' norte-americanas não são mais do que "transfigurações fracamente conceitualizadas, infinitamente renovadas e atual izadas... dos estereótipos raciais mais comumente usados" que servem para justificar a "dominação dos brancos sobreos negros" na sociedadenorte-americana. D epois de notar o grande peso da opressão racial na história dos Estados U nidos, asseveram os autores que os discursos "raciais" derivados dos EU A servem, antes de mais nada, para "ocultar" a "divisão de casta" dentro da sociedade norte-americana "ao submergi-la no universo de visões diferenciadoras 'revistas' através delentes dosEU A por meio da 'globalização'" (idem: 42).

Para provar seu argumento, Bourdieu eW acquant voltam-se para o papel dos EU A no debate "em torno da 'raça eidentidade'" no B rasil, marcado por "uma intrusão etnocêntrica similar, ainda que mais brutal" do que aquelas criticadas no caso europeu, "uma que é ainda mais ameaçadora, já que toca em um domínio mais próximo à realidade política". O súltimos vinte anos de pesquisa sobre a desigualdade racial no Brasil são apresentados como uma imposição unilateral dos Estados U nidos em uma sociedade substancialmente sem racismo. 0 processo que descrevem é aquele no qual

[...] uma representação histórica, oriunda do fato de quea tradição [norte] americana sobrepõe a uma realidade social infinitamente mais complexa uma dicotomia rígida entrebrancose negros [...] impõe-se a países onde os princípios operativos de visão e divisão das diferenças étnicas, codificadas ou práticas, são bem diferenteseque, como o B rasil, eram até recentemente considerados como contra-exemplos ao "modelo [norte] americano". (idem: 44, 53, 44-5)

As iniciativas dos Estados U nidos a respeito da questão racial no Brasil - insistem - são elaboradas "para encorajar os líderes do M ovimento $\mathrm{N}$ egro [...] a denunciarem a categoria do pardo (um intermediário entre o branco e o preto, que se refere a pessoas de aparênciafísica mista)" de forma a "mobilizar todosos brasileiros de origem africana sobre a base de uma oposição dicotômica entre 'afro-brasileiros' e 'brancos'". Além disso, estes estudiosos seguem "o mito [norte-americano] segundo o qual todas as sociedades são 'racistas', , mesmo aquel as nas quais "as relações 'raciais' parecem ser, à primeira vista, menos distantes ehostis" do quenosEstados U nidos(idem: 47, 44). "A difusão da doxa racial dos EU A dentro do campo acadêmico brasileiro" - Bourdieu e Wacquant sugerem - "tem sido incentivada por financia- 
mentos das fundações norte-americanas para programas de pesquisa eintercâmbio acadêmico sobrequestões raciais em instituições brasileiras", iniciativas governadas - notam com irritação por "critérios de ação afirmativa dos EU A", que, acreditam, geram "problemas in superáveis" no B rasil, dada a ausência da dicotomia branco/negro. "A corrente intelectual neste intercâmbio", insistem, "flui apenas em uma direção" com os brasileiros, especialmente nos movimentos negros, sen do incentivados a retraduzir " problemas sociais de relevo atuais em um vocabulário importado dos EU A (etnicidade, identidade, minoria, comunidade, fragmentação etc.)" (idem: 46, 50).

É curioso, dadas as suas posições indiferentes à cor, que Bourdieu e W acquant decidam chamar a atenção em especial à "raça" de um pesquisador, $\mathrm{M}$ ichael $\mathrm{H}$ anchard, descrito como um "cientista político afro-americano", apesar de não apresentarem autores norte-americanos com quem concordam, como C arl Degler, como "historiadores euro-americanos". Bourdieu e Wacquant julgam a monografia de 1994 deM ichael $\mathrm{H}$ anchard, 0 rfeu e o Poder, como sendo o epítome do imperialismo cultural dosEU A nestaárea. Estetexto é "um veneno etnocêntrico", insistem, parao qual antídotos devem ser buscados edivulgados (como um recente livro escrito por outro autor norte-americano, Anthony $M$ arx, que não éidentificado como um "cientista político euro-americano", e cujos argumentos, de fato, não são comparados aos de H anchard) (idem: 44).

A acusação a H anchard é simples e direta. $\mathrm{H}$ anchard - sugerem Bourdieu e W acquant - se esquece que as conceitualizações raciais norte-americanas

[...] têm suas raízes na realidade complexa e controversa dos [Estados U nidos como] uma sociedade histórica particular, agora tacitamente constituída como um modelo para todas as outras euma unidadede medida para todas as coisas. [Assim, ele] traz consigo todas as particularidades e os particularismos [do caso norte-americano] sem nunca levá-los em consideração conscientemente.

Em particular, ele aplica categorias raciais norte-americanas à situação brasileira, com o seu contínuo decor, eao mesmo tempo faz "da história, particular, do M ovimento dos D ireitos Civis dos Estados U nidos, o padrão universal para todos os grupos oprimidos pela cor (ou casta)". 0 estudo de H anchard - defendem - é ainda mais minado pela sua recusa dogmática em expor suas idéias

\section{6}


ou desejos "ao menor testeempírico" em temos da realidadebrasileira" (idem).

Para Bourdieu eW acquant o problema com 0 rfeu e o Poder vai ainda mais longe. Como outros norte-americanos, $\mathrm{H}$ anchard procura "[...] provar que, contrariamenteà imagem que os brasileiros têm de sua própria nação, o país das 'três tristes raças' [...] não é menos 'racista' do que outros e que os 'brancos' brasileiros não têm nada a invejar dos seus primos norte-americanos neste sentido". Com efeito, dizem queH anchard acredita que "o queépior, 0 racismo mascarado brasileiro deveria ser visto como o mais perverso, justamentepor ser dissimulado enegar-sea si próprio" (idem).

Em vista desta linguagem desdenhosa e altamente derrogatória, o leitor poderia, com razão, esperar que os autores oferecessem uma crítica enfática e cuidadosamente articulada do livro de $\mathrm{H}$ anchard. Se seus argumentos fossem preci sos, seria rel ativamente fácil citar capítulos e páginas para demonstrar a natureza flagrante dos erros de $\mathrm{H}$ anchard. Porém, para nossa surpresa, os autores não oferecem uma única citação ou referência direta às páginas de 0 rfeu e o Poder. Ainda que prejudicados por um conhecimento superficial daliteratura rel evantenas Ciências Sociaissobre a questão racial, eles oferecem uma representação escandalosamenteerrônea das proposições centrais desta recenteesignificante contribuição para o debate em torno de raça, cor enação no Brasil. Com efeito, osleitores familiarizados com o livro deH anchard podem imediatamente reconhecer a natureza falsa dos argumentos de Bourdieu eW acquant sobre o uso da comparação entre Brasil e Estados U nidos em O rfeu e o Poder.

\section{"Raça", "Racismo" e "M obilização Racial" em 0 rfeu e 0 Poder: ${ }^{4}$ U ma Perspectiva N orte-Americana a Respeito do "Q uebra-C abeça" ou da "C harada" B rasileira}

Bourdieu e W acquant acusam $\mathrm{H}$ anchard de mobilizar três "idéias fora do lugar" que definem como sendo essencialmente norte-americanas. Contudo, estão simplesmente errados quando asseveram queH anchard utiliza categorias raciais oriundas deuma conceitual ização norte-americana de "raça" definida por descendência. De fato, $\mathrm{H}$ anchard rejeita, tanto em um nível teórico quanto prático, um conceito essencial ista (quanto mais biológico) deraça. "Raças" ediferenças raciais, insiste, são construídas socialmente ( $\mathrm{H}$ anchard, 1994a:14; 1991:86-7) erejeita enfaticamentea 
noção dequea "raça" seja uma quantidade conhecida ou quepossa ser lida ou entendida automaticamente devido à sua ligação a um fenótipo (aparência).

A abordagem construcionista de $\mathrm{H}$ anchard à raça, que não é ponto pacífico entre as comunidades afro e euro-norte-americanas, permite que ele admita francamente que

[... ] em um país como o Brasil [...] qualquer abordagem queautomaticamente pressuponha a existência de duas ou mais 'raças' fenotipicamente distintas limitaria severamente os esforços do pesquisador para explicar empírica e teoricamente a 'raça' em questão [... . . N ão há 'dados' para as filiações étnicas ou raciais [e seus] significado einterpretação estão sempre sujeitos a revisão, mudança [e] negociação. (idem, 1994a:15)

A peculiaridade brasileira, conclui, reside no fato de que "a ausência de 'dados' raciais eétnicosémais profunda [no Brasil ] do que em outros países" (idem).

D esta maneira, $\mathrm{H}$ anchard está longe de oferecer uma versão reciclada do "conceito popular" norte-americano de raça. "O termo raça utilizado neste estudo", escreve $\mathrm{H}$ anchard, "refere-se ao emprego de diferenças fenotípicas como símbolos de distinção social [...]. Estes símbolos, significados e práticas materiais diferenciam sujeitos dominadores e subordinados de acordo com suas categorizações raciais". D iferentemente de Bourdieu e W acquant, todavia, eledefato insistequea "raça," nestecaso, énão apenas um marcador de diferen ças fenotípicas, mas também de status, classee poder político. N este sentido, "as relações raciais são relações de poder", através das quais emergem "modos de consciência racial", definidos mais geral mente como "o resultado dialético do antagonismo entre dois ou mais grupos definidos como 'raças' em uma dada sociedade" (ibidem:14; 1991:86-7). Discordando de uma posição puramente racial, ele caracteriza como problemática "a própria noção de uma consciência singular e unitária que possa mobilizar um grupo social inteiro [...] tendo em vista o grandenúmero devariáveis divisoras (sexo eclasseentreelas) que complicam as formas de identificação". Finalmente, el e também adverte que "um esforço não-crítico de enfatizar a autonomia relativa da dominação racial e étnica vis-à-vis relações de classe" corre o "risco de um reducionismo determinista" (ibidem:97).

A adoção por parte de H anchard do conceito de "raça social" (um termo cunhado por Charles Wagley, 1959) traz consigo o reconhecimento de que a dinâmica da subordinação de povos descendentes de africanos no Brasil e nosEU A, eas estruturas discur-

\section{8}


Passosem Falso da Razão Antiimperialista...

sivas que as envolvem, diferem de forma significativa. D iferente mentede seus críticos franceses, $\mathrm{H}$ anchard reconhecequeháracismos enão simplesmenteum racismo em jogo na diáspora africana: a existência, não de um "racismo no singular", mas, ao invés, no plural, para usar as pal avras de Paul Gilroy (ibidem:17). N egando que existam racismos melhores ou piores, $\mathrm{H}$ anchard reconhece claramenteque os sistemas de dominação racial variam não apenas em sua lógica intelectual, modos de operação e de manifestação, mas em seu impacto nas subjetividades dos grupos tanto super quanto subordinados. Assim, $\mathrm{H}$ anchard junta-se a outros estudiosos que recentemente têm chamado a atenção para a variação nas formas e termos da opressão racial e, conseqüentemente, nas formas de resistência (Butler, 1997; Segato, 1998).

Assim como em seus outros argumentos, Bourdieu e W acquant estão enganados na forma como situam 0 rfeu eP oder dentro do contexto de setenta anos de pesquisa e discussão contínuas das relações de raça nas Américas, com uma ênfase especial na experiência negra no Brasil. ${ }^{6} \mathrm{D}$ esde os anos 30 , várias gerações de estudiosos - brasileiros, norte-americanos, europeus e africanos - têm lidado com a dificuldade de se incorporar o Brasil no mesmo quadro conceitual que o caso específico dos EU A. As posições teóricas têm mudado com o tempo, dependendo da conjuntura política dentro das respectivas sociedades, mas a discussão tendeu a girar em torno da questão de onde colocar a ênfase- senas diferenças ou nas sem el hanças entre a experiência histórica da escravidão racial e suas repercussões nos EU A e Brasil (H ellwig, 1992; G uimarães, 1995a, 1995b). Em nenhum caso, no entanto, os estudiosos negam que se possa encontrar tanto semelhanças quanto especificidades nas histórias dos povos descendentes de africanos nestas duas sociedades do $\mathrm{N}$ ovo $\mathrm{M}$ undo.?

As críticas de Bourdieu e W acquant sobre $H$ anchard teriam sido, com efeito, bem mais apropriadas se fossem dirigidas contra a tendência dominante da pesquisa sobre raça e cor nos anos 80 . Foi durante o final dos anos 70 que uma nova militância a respeito de raça e racismo emergiu tanto no Brasil, com a fundação do pequeno mas bem visível M ovimento $\mathrm{N}$ egro U nificado - MNU, quanto entre estudiosos brasileiros e estrangeiros. Com uma natureza denunciadora, esta onda de pesqui sa radical izou a crítica revisi onista das décadas de 50 e 60, que foi a primeira a atacar o argumento de que o Brasil não seria racista. O perando em solidariedadecom os protestos negrosno Brasil, a geração de estudiosos depois de 1978 tendeu a adotar uma abordagem quantitativa com vistas 
John French

a provar, de uma vez por todas, a falsidade do mito da democracia racial. A o fazer isso, esperava fortalecer os movimentos negrosincipientes dando-Ihes apoio intelectual por meio do argumento de que o sistema racial brasileiro seria mel hor entendido como fundamental mente birracial, em vez demultirracial, equeas desigualdades que afetam os povos descen dentes de africanos estariam relacionadas a padrões abrangentes de preconceito e discriminação.

Em sua forma mais enfática, a pesquisa realizada depois de 1978 asseverava que branco e negro deveriam ser consideradas as categorias raciais sundamentais no B rasil, em vez denegro, pardo e branco, ou branco e não-branco (para a argumentação mais extensiva a este respeito, ver Andrews, 1991a; 1998). Ao fazer isso, pode-se dizer que se adotava a tática política do M N U como a base intelectual para a sua análise. ${ }^{8}$ Ao mesmo tempo, o objetivo era claro: expor a falsi dade da prolongada defesa do B rasil como uma sociedade racialmente livre por meio da mobilização de dados estatísticos (especialmentea PN AD, recentemente disponível) deforma a revelar, em oposição à crença comum a brasileiros de todas as cores, que havia desigualdades raciais, independentemente de como fossem medidas. $\mathrm{N}$ o mínimo, estudiosos como $\mathrm{N}$ elson do Valle Silva (1978, 1985), Carlos A. H asenbalg (1979a, 1979b, 1985), Charles W ood e José de M agno Carvalho (1988) obtiveram resultados surpreendentes que se punham em contradição à forte opinião nacional de que não haveria impedimentos raciais para a ascensão social ou o sucesso. ${ }^{9}$ Além disso, elestendiam a refutar com dados estatísticos a suposição de que os brasileiros de raça mista ocupavam uma posição "média" entre negros ebrancos, a hipótese da existência de "uma porta de escape mulata", como foi batizada por C arl D egler (1986).

Fazendo uma retrospectiva, a ênfase provocadora destas obras com relação à semel hança entre osEU A eo Brasil poderia ser vista como oriunda de um entendimento errôneo, ainda que louvável, a respeito do que constitui a solidariedade anti-racista. Q uando vulgarizada e convertida em discursos de comício, no entanto, esta postura iconoclástica chega quase a postular um dogma racial essencialista ou primordialista (ou seja, a opinião de que, nas palavras de $\mathrm{M}$ ichael $\mathrm{H}$ anchard, os

[...] negrostêm uma posição unilateral em rel ação à sua própria negritude (identidade e experiência) [ou seja, ] a pressuposição de que todos os negros são osmesmos, oprimidos da mesma maneira em todososlugares e que devem reagir de uma forma absoluta [e idêntica]. (H anchard, $1991: 91-2)^{10}$

\section{0}


Passosem Falso da Razão Antiimperialista...

$\mathrm{H}$ anchard reconhece corretamente as limitações de tal homogene ização e dos "discursos totalizadores dentro da experiência [da] diáspora africana", e francamente admite que a esperança em torno de "uma afinidade universal e absoluta para e entre os povos da diáspora africana tem sido tão ilusória quanto a formação de um proletariado internacional" (ibidem:92).

D esta forma, $\mathrm{H}$ anchard recusa-se a adotar uma solidariedade retórica baseada em uma visão romântica de traços comuns. Sua análise também não depende da esperança, momentaneamente defendida nos anos 80, de que as resistências euro e afrobrasileira à mobilização racial evaporariam sob o impacto combinado de uma nova geração de militância afro-brasi lei ra e de estudos engajados. Este tipo de resposta solidária mais simples é meIhor exemplificado pelos escritos do sociólogo norte-americano H oward W inant, que defendia, por exemplo, quejá em 1988 "um consenso substancial existia entre os negros [brasileiros] [e até mesmo entre a maioria dos brancos] de que a 'democracia racial' era uma farsa euma fraude equeo racismo continuava a dominar a sociedade brasileira" (W inant, 1996:86-87). Em contraste, especialistas em Brasil, incluindo os recentes trabalhos de Twine (1997) e Sheriff (1997), são bem mais real istas a respeito da profundidade e da extensão deste desmascaramento, altamente desejado, do racismo brasileiro. Como nota Richard $\mathrm{G}$ raham, o mito da democracia racial brasileira "foi completamente demolido no meio acadêmico nos últimos trinta anos, mas permanece profundamente entrinchei rado na opinião popular e da elite, até mesmo entre os negros" (G raham, 1995). M itchell também nota a "insistente persistência da credibilidade deste mito" e seu entrincheiramento na cultura brasileira. "D iferentemente de pesquisadores anteriores, [que] estavam preocupados com a denúncia direta do mito da democracia racial" - continua - "H anchard aponta o poder continuado do mito ao incorporá-lo numa análise sistemática do protesto negro [, num esforço para] explicar as persistentes questões que se seguiram à erosão do mito da democracia racial nos círculos acadêmicos" (M itchell 1995).

A pesar de crítico em relação ao mito brasileiro da harmonia racial, $\mathrm{H}$ anchard insiste em que as diferenças entre o Brasil e os Estados U nidos devem ser confrontadas e não apenas varridas para debaixo do tapete em nome da solidariedade. 0 reconhecimento detais diferen ças não leva $\mathrm{H}$ anchard, no entanto, a asseverar quea experiência negra no Brasil seja total mente diferente da dos EU A (esta éa posição defendida por Bourdieu eW acquant). Em vez dis- 
John French

so, ele insiste, com acerto, que as características distintivas da dinâmica racial eétnica brasileiras não impossibilitam análises comparativas com outras sociedades, até mesmo os EU A (H anchard, 1994a:78). $\mathrm{H}$ anchard propõe, de forma sensata, trazer o Brasil para a discussão do Atlântico N orte através de uma abordagem sólida que leva em consideração o diferente à luz do similar. Ainda que reconheça divergências fundamentais no escopo, escala e intensidade da "mobilização racial" no Brasil, $\mathrm{H}$ anchard, no entanto, lembra a seus leitores que "a au sência de solidariedadeafro-brasileira não é total", nem mesmo se "a sua presença não tenha foco ou direção" quando comparada aos exemplos norte-americano ou sul-africano (ibidem:80).

$\mathrm{O}$ enfoque explícito e restrito de $\mathrm{H}$ anchard na mobilização política baseada na raça o leva a ignorar questões "não-políticas" da cultura ou identidade afro-brasileiras. ${ }^{11}$ I sto o faz capaz, todavia, deformular, da forma mai spersuasiva, o desafio que comparativistas têm diante de si: "Por que não houve nenhum movimento social afro-brasileiro continuado no Brasil e que pudesse ser comparado ao movimento dos direitos civis nos EU A ou às rebeliões nacionalistas na África do sub-Saara e em partes do N ovo M undo depois da Segunda G uerra?" (ibidem:5). Como é possível, continua, que o "Brasil, o país com a maior população negra no N ovo $M$ undo, tenha uma população negra com um dos mais baixos níveis de conscientização racial nas Américas?" (ibidem:95). ${ }^{12}$

Graham (1995) observa que o estudo deH anchard abriu novos caminhos de pesquisa, justamente por causa da nitidez com a qual ele abordou a questão da razão do protesto negro, que existee aconteceno Brasil, edos "[...] movimentos de solidariedadenegra, que têm sido tão poucos e esporádicos, com vida curta, e que até agora não geraram resultados. Por que o mito da democracia racial persiste? Como a dominação racial é construída e mantida? 0 nde estão seus limites? C omo é posta em questão e contestada?" Estas são precisamente as "questões [que] incomodam aquel es que estudam a subordinação racial no Brasil", notou a brasileira D enise Ferreira da Silva, assim como

aqueles que estudam relações de raça comparativamente, e, ainda mais importante (de um ponto de vista de auto-interesse) [...] aqueles entre nós envolvidos no projeto de incentivar a emancipação racial no Brasil [... . . C omo pode a exclusão racial ser possível sem a discriminação aberta, e sem mecanismos mais ou menos explícitos de segregação racial? Por que níveis tão altos de exclusão racial não conduzem à emergência de uma consciência de raça, e às conseqüentes mobilizações políticas entre

\section{2}


Passosem Falso da Razão Antiimperialista...

brasileiros negros? Por que os negros brasileiros não possuem uma identidade (racial) separada? (Silva, D ., 1998:222, 204)

H anchard aborda estas difíceis questões - que não são nem mesmo compreendidas por Bourdieu e Wacquant - através de uma estratégia de pesquisa qual itativa bem específica. Tendo em vista seus interesses altamente delineados, ele não estuda os brasileiros descendentes de africanos como um todo, mas apenas a minoria demilitantes negros que defato construíram uma "identidade afro-brasileira consciente de si mesma" baseada na politização da diferença racial. "Com pôde emergir tal forma de consciência racial politicamente conseqüente", $\mathrm{H}$ anchard pergunta, "em uma sociedade tão avessa ao conceito de 'raça' etão hostil à mobilização de'diferenças raciais'?" (H anchard, 1994a:79). Como e por queos brasileiros de ascendência africana obtêm uma consciência de "raça", "assumem sua negritude", ${ }^{13}$ e decidem-se a agir com ela de forma política? Asreflexões de $\mathrm{H}$ anchard a respeito destes assuntos são derivadas de entrevistas feitas com sessenta líderes de movimentos, em um esforço para entender "como, baseado em incidentes de suas vidas privadas, el es al cançaram" sua posição de militância negra. ${ }^{14}$

Em sua preocupação com a identidaderacial, 0 rfeu eo Poder representou uma mudança significativa na literatura acadêmica em 1994, haja vista a ligação entre a ênfase ainda predominante em dados raciais quantitativos e os objetivos anti-racistas comuns. As estatísticas a respeito da desigualdade racial, afinal de contas, pareciam oferecer evidências objetivas para serem usadas em denúncias e na conscientização, em contraste com as obscuras discussões sobre a identidade "racial" de brasilei ros de origem africana, que pareciam minar aluta ao introduzir uma "confusão" subjetivista. $\mathrm{N}$ adando contra a corrente, $\mathrm{H}$ anchard re-introduziu uma ênfase "antropológica" mais antiga sobrea "raça", entendida como um fenômeno discursivo, efez isso precisamentequando um proeminente estudioso, Thomas Skidmore, havia declarado que os dias para tal tipo de pesquisa já tinham passado, já que dados "duros" sobre raça estavam agora disponíveis (para o potencial pleno de uma rica abordagem atropológica, cf. as etnografias imensamente estimulantes de Burdick, 1998, e Sheriff, 1997a). N o mesmo artigo de 1992, Skidmore também dividia a opinião, então preval ente, de que o Brasil estaria se dirigindo para a birracialidade, enquanto os EUA, em contraste, estariam se tornando mais multirraciais (Skidmore, 1992, 1993). 
John French

O rfeu eo Poder não foi único em seu exame dos movimentos da "consciência negra" que surgiram durante as intensas revoltas populares etrabal histas que marcaram a luta contra o regime militar brasileiro no final dos anos $70 .{ }^{15}$ Contudo, a abordagem de $\mathrm{H}$ anchard é original, até mesmo controversa, precisamente porque, como salienta Fry (1995), $\mathrm{H}$ anchard ébem "diferente dos autores queescreveram sobre os movimentos negros brasileiros antes dele, que, de uma forma ou de outra, estavam ligados a eles, etendiam a repetir a retórica dos comícios". Seu distanciamento da forma simples de solidariedade é baseado em sua posição como um afro-norte-americano com uma visão diaspórica que procura entender mel hor a base eos obstáculos para a criação de uma política negra no Brasil. Sua preocupação é, nas pal avras de M itchell, com "as possibilidades elimitações da militân cia negra" dentro da parte brasileira da população do N ovo M undo que é descendente de africanos (M itchell, 1995).

$\mathrm{H}$ anchard oferece comentários maissugestivos em rel ação às dificuldades dese mobilizar a identificação racial no Brasil, em um capítulo intitulado "A Formação da Consciência N egra". D a mesma forma que os estudiosos anteriores, reconhece que a variabilidade na autodesignação no B rasil e a falta de categorias raciais dicotômicas fazem do fenótipo "uma base ainda mais precária para a mobilização coletiva do que em outras sociedades". Todavia, utiliza as experiências devida de vários militantes para demonstrar que a experiência afro-brasileira é marcada por uma relativa, mas de forma al guma absoluta, "falta de identificação racial". Sugereque, para apreender esta distinção, o fenômeno deve ser descrito pela distinção entre semel hanças fracas ("uma questão de disposição, atitude) e semelhanças fortes, bem menos comuns, que surgem e "operam em momentos históricos específicos" de polarização e conflito ("o momento histórico") (H anchard, 1994a: 78, 80).

Fiel a uma abordagem construcionista da questão da raça, $\mathrm{H}$ anchard enfatiza assim a trajetória distinta do Brasil, quando comparada à de outros países, de uma forma similar, mas menos sistemática do que no recentelivro de Anthony M arx (1998), que é elogiado por Bourdieu e W acquant como um antídoto a $\mathrm{H}$ anchard. D iferentemente dos EU A ou da África do Sul, "a ausência deameaças externas ede uma sociedade dicotomicamentesegregada [no Brasil] impediram a necessidade de semelhanças fortes em termos absolutos e unidimensionais" que se combinam à ausência do tipo "de instituições e projetos coletivos [negros] auto-suficientes" no Brasil, que constituíram, por assim dizer, "o prêmio de

\section{4}


Passosem Falso da Razão Antiimperialista...

consolação" no caso dos EU A. U sando a idéia de uma família de semel hanças, fortes e fracas, $\mathrm{H}$ anchard sugere que $\mathrm{o}$ objetivo dos movimentos de consciência negra é tornar as "semel hanças fracas em fortes". Esta identidade oposicionista afro-brasileira, admite, ainda não está "difundida o suficiente para catalisar a massa dos afro-brasileiros" e, assim, está

[...] altamente em funcionamento [somente] entre os militantes afro-brasileiros e seus [pequenos] círculos [...] [naqueles lugares] onde 0 movimento negro tem uma força relativa [...]. Até mesmo [os militantes negros], queestariam livres para pôr em prática uma versão maiscontundente da identidade afro-brasileira entre as massas, hesitam [em fazer isso], [...] por medo de se alienarem em uma sociedade onde semel hanças fortesnão são mutuamentereforçadas [...]. [H á, desta maneira,] dificuldades práticas para se estender semelhanças afro-brasileiras fortes para um público de massa. (H anchard, 1994a:78-80, 82)

O rfeu eo Poder demonstra, deforma convincente, queo surgimento de uma agenda racial de oposição entre alguns afro-brasileiros ajuda a iluminar a dinâmica da subordinação e resistência raciais no Brasil, não importa quão limitado o seu apelo popular até agora. 0 livro oferece um contribuição ao ajudar os norte-americanos a entender não apenas "porque afro-brasileiros não são afro-norte-americanos" (título da excelente palestra de Anani D zidzienyo, um brasilianista da Brown U niversity, nascido em $\mathrm{G}$ ana, epor muito tempo um estudioso da raça ecor no Brasil), mas também porque "o Brasil não é(como) osEstados U nidos" em termos de negritude (o subtítulo de um recente e extraordinário artigo da socióloga brasileira e militante negra D enise Ferreira da Silva, 1998).

\section{"Raça" e M itologias Sociais no Brasil, França e Estados U nidos: D ois Pesos, D uas M edidas e Má-Fé}

A indignação com a qual Bourdieu eW acquant condenam O rfeu e o Poder, sem um compromisso ou argumentação sérios, pode apenas advir de uma confiança de que, de fato, eles conhecem al go sobrea raça e cor no "país 'das três raças tristes'" (um clichêen saístico ultrapassado e conden scendente sobre o "caráter nacional" brasileiro). A pesar do fato de que "as relações raciais [no B rasil] aparentam à primeira vista ser menos distantes ehostis" do que nos Estados U nidos - declaram - o imperialismo cultural dos EU A está intensificando seus esforços em "impor" seu peculiar e 
John French

venenoso entendimento da raça na visão particular que o Brasil tem a respeito da diferença étnica. A existência no Brasil de um contínuo de cor do negro ao branco, com centenas de "categorais intermediárias e parcialmente em intersessão", combinadas com a au sência de hipodescendência - argumentam - está em contraste flagrante com as categorias raciais rígidas e dicotômicas dosEU A. Estes autores apontam para a ironia de que, no mesmo instanteem que agentes dos EU A pregam uma luta racial de "'afro-brasileiros' contra 'brancos', pessoas de origem mista [nosEU A], incluindo os chamados 'negros', estão tentando obter reconhecimento como uma categoria [norte] americana de raça mista, em vez de serem 'forçadamente' classificados sob o rótulo único de 'negros'" (Bourdieu \& W acquant, 1999:44-5, 47).

Ainda que criticando os EU A por sua inflexível insistência no mito do que seria uma sociedade excepcionalmente fluida, aberta e sem classes, Bourdieu eW acquant denunciam que os norte-americanos estão envolvidos em uma agressão imperialista brutal, através de uma falsa acusação de racismo, na "imagem que os brasileiros têm de sua própria nação". A té recentemente - enfatizam - o Brasil era considerado um contra-exemplo do "'modelo' [racial] [norte] americano (de acordo com o clássico estudo do [historiador norte-americano] C arl D egler)"16 e continuam, citando um outro artigo "clássico" agora do antropólogo norte-americano C harles W agley, visando mostrar que o conceito de "raça" varia nas A méricas (ibidem:44-5). N o entanto, a leitura de D egler da literatura brasileira levou-o a concluir que "o preconceito e discriminação de cor [realmente] existem no Brasil, como ainda existem nosEstadosU nidos" (D egler, 1986:268). E o ciclo de pesquisas patrocinado pela U nesco nos anos 50 sobre relações raciais, no qual W agley foi uma figura-chave, foi "unânime ao detectar o preconceito racial", ainda quealguns, como Wagley, "fossem tímidos ao interpretar o preconceito observado" (Guimarães, 1999:77; Fontaine, 1980:123-4). ${ }^{17}$ C omo recentemente escreveu J ohn Burdick, desde 1945 "três gerações de estudiosos produziram uma prateleira de obras que revelam a realidade da discriminação brasileirabaseada na cor [... ] a questão não émais se, mas como, a cor de um brasileiro influencia a sua vida" (Burdick, 1998:1).

Com todas as suas peculiaridades, o sistem brasileiro de raça e cor ainda é, por sinal, baseado em uma hierarquia racial clara na qual a branquidão/europeidade é valorizada e a negritude/africanidade é estigmatizada. Estas normas e práticas estão socialmente ligadas a estereótipos racistas e imagens normativas, somáticas e

\section{6}


Passosem Falso da Razão Antiimperialista...

derrogatórias, que degradam a negritude (Blanco, 1978). N este sentido, "o racismo no estilo brasileiro" difere do racismo nos EUA fundamentalmente em seu foco: no Brasil, o preconceito contra a aparência (preconceito de marca ou fenótipo) versus o preconceito contra origem ou descendência (preconceito de origem ou genótipo) de acordo com a formulação clássica do sociólogo brasileiro O racy N ogueira (1959, 1985; cf. também C aval canti, 1999).

Bourdieu eW acquant tentam minimizar a realidade do preconceito e da discriminação no Brasil, contrastando a situação brasileira com a "ostracização racial ou estigmatização sem direito a recurso ou reparação" à qual acreditam queosnegros nos Estados U nidos estão submetidos. D epois de descrever a condição americana como se pouco tivesse mudado desde a década de 50, procedem a caracterizar a relação entre negros ebrancos nos EU A como "mais próxima daquela entre castas definitivamente definidas edelimitadas" (uma declaração particularmente controversa, que é simplesmente jogada, sem muita elaboração ou justificativa).

Contudo, o contrasteque Bourdieu eW acquant fazem entre Brasil e EU A, grosseiro e exagerado, já era anacrônico em 1971, quando $\mathrm{D}$ egler publicou $\mathrm{N}$ em Preto $\mathrm{N}$ em Branco. D egler chegou à conclusão que os acadêmicos e jornalistas durante 0 período pré-D ireitos Civis nos EU A comparavam as relações raciais no Brasil e Estados U nidos de forma bem rotineira, "normalmente para o descrédito do último". Tais estudos inevitavel mente eram "muito bem recebidos por norte-americanos que desejavam salientar a natureza racista das relações de raça nos EU A", observa, e tiveram uma forte aprovação no Brasil "por parte daqueles que desejavam enfatizar a democracia racial em seu país". Todavia, muitos estudiosos brasileiros, mesmo naquela época, rejeitaram esta comparação entreEU A eBrasil, justamente porque ela servia para "obscurecer, se não negar", a existência de preconceito e discriminação no Brasil: "tudo vai bem [racialmente] porque no Brasil asituação não é tão ruim quanto no interior do sul [dosEU A]" (nas pal avras de Luiz Costa Pinto em 1952 [D egler, 1986:286]). ${ }^{18}$

Tendo lido o "clássico" livro de D egler com a mesma falta de cuidado que 0 rfeu e o Poder, Bourdieu eW acquant não percebem que $D$ egler chega, na realidade, à mesma conclusão "imperial ista" que rejeitam: que, depois de 1960, os dois países são mais similares do que diferentes em termos de raça. Já que as práticas segregacionistas "que outrora distinguiam os EU A do Brasil em sua maior parte não mais existem", escreve D egler, "talvez tenha chegado a 
John French

hora de reconhecer que hoje a comparação das relações de raça nos dois países não é sempre favorável ao B rasil"; el e chega mesmo a prever "a possibilidade de uma discriminação crescente" e uma ampliação da "tensão racial e preconceito de cor no Brasil" (D egler, 1986: 268; cf., também, Andrews, 1991b:4, 24-44)!

Contudo, Bourdieu e Wacquant ainda poderiam defender-se aqui. Afinal de contas, declaram com um floreio, o Brasil é marcado pela "ausência virtual" (uma expressão estranhamente obscura) de "duasformastípicas deviolência etno-racial dosEU A: o linchamento e os distúrbios urbanos" (Bourdieu \& Wacquant, 1999:45). Tal ingenuidade é tocante, como Kim Butler recentemente observou:

Apesar deser verdadeque os horrores do terrorismo racial queocorreram nos Estados U nidos, tal como o linchamento, não terem acontecido no Brasil, isto não nega o impacto social dasideol ogias do racismo eracialismo. Tal raciocínio confunde racismo com animosidade, violência epreconceito, nenhum dos quais tem necessariamente que estar presente em uma ideologia racista. (Butler, 1998:49)

A lógica por detrás dos comentários de Bourdieu e Wacquant a respeito dos linchamentos por raça é também surpreendentemente limitada. U ma das observações mais importantes de W agley, em seu artigo de 1959, foi chamar a atenção para a nature za racializada das classes sociais em países da América L atina como o Brasil, onde ser mais claro ou escuro na aparência é fortemente correlacionadao com os extremos altos ebaixos da estrutura social. $\mathrm{N}$ ão é fora de propósito relacionar estas realidades aos altos níveis de violência no Brasil, não apenas à violência estrutural, mastambém aos linchamentos, esquadrões da morte eassassinatos promovidos por policiais (dentre os quais o massacre de crianças de rua recebe a maior aten ção). Asvítimastendem a ser, bem mais, negras do que aqueles "que contam" e, apesar de não serem mortos explicitamente por causa de sua "raça”" (queéimportante), com certeza a sua cor faz com queas classes média eal ta, que são em sua grande maioria brancas ou claras, ignorem e se distanciem do destino de tais "marginais" ou "favelados".

Há ainda uma ironia final em relação à combinação que Bourdieu eW acquant fazem de uma caracterização peculiar e indevidamente negativa da dinâmica racial dos EU A e uma leitura generosa e positiva demais do panorama racial brasileiro. Ao realizarem isto, eles não fazem mais do que ocupar o último lugar em uma longa lista de observadores e cientistas sociais estrangei ros e

\section{8}


Passosem Falso da Razão Antiimperialista...

ingênuos, que têm sido iludidos pela "ambigüidade e a natureza evasiva da ideologia racial latino-americana, especial mente na sua forma brasileira", como notou PierreF ontaineem 1980, sendo levados à conclusão errônea "de que não haveria problemas raciais [no Brasil] (apesar de esta posição não ser maismantida entreosestudiosos sérios)" (Fontaine, 1980:111). ${ }^{19} \mathrm{D}$ e fato, nas últimas dé cadas, não houve uma única tentativa, por parte de brasileiros nos meios acadêmicos, de defender a hipótese, sustentada por evidências em oposição a ideais ou mitos, de que o Brasil éuma sociedade sem racismo ( para uma bela seleção da pesquisa sobrea desigual dade racial levada a cabo por cientistas sociais brasileiros, cf. R eichmann, 1999). Afirmações simples sobre a democracia racial brasileira são encontradas apenas na crença popular de brasileiros que não pesquisam o assunto.

0 mito da democracia racial brasileiraé, neste sentido, similar em suas linhas gerais ao mito dos Estados U nidos como sendo uma sociedadeúnica em sua meritocracia eabertura, com oportunidades para todos que se esforçam. $\mathrm{N}$ o entanto, Bourdieu eW acquant atacam enfaticamente esta doce imagem que os EU A gostariam de ter de si mesmo. "Estudos comparativos rigorosos" baseados em pesquisas estatísticas - dizem - desmascararam a noção norte-americana de que os EU A seriam uma sociedade excepcionalmente fluida, com um alto grau de mobilidade social, em contraste às rígidas estruturas sociais do Velho $M$ undo (Bourdieu $\&$ W acquant 1999:51). Todavia, esta tática de crítica (os EU A são como a Europa), assim como o tipo de provas utilizadas, também caracterizavam o estudo brasil eiro sobrea raça depois de 1978, que é justamente atacado por Bourdieu e W acquant. U ma contribuição magnífica neste sentido foi 0 excelente artigo, de 1992, de G eorge Reid Andrews, intitulado "D esigualdade Racial no Brasil e Estados U nidos: U ma Comparação Estatística," que reverteu a convicção brasilei ra de que os negros obviamente estariam em uma melhor condição no Brasil do que nos EU A.

Bourdieu e W acquant claramente lidam com dois pesos e duas medidas quando comparam os EU A eo Brasil, pois oferecem uma descrição excessivamente dura e negativa da situação racial nos EU A e são intolerantes em relação à sua mitologia nacional; em oposição a isso, oferecem uma descrição excessivamente tolerante e positiva da situação racial no Brazil, ao mesmo tempo que acolhem sua mitologia nacional sem crítica. Como chegaram a ter esta postura de defensor da honra nacional brasileira contra os norte-americanos? E o que levaria pensadores críticos franceses, 
John French

oponentes proeminentes do neoliberalismo, a desculpar a desigualdade racial no Brasil e partir com quatro pedras em cada mão contra críticos nacionais e estrangeiros de uma democracia racial que estál onge de ser perfeita? Por quesão tão impiedosos para com as ilusões dos EU A e tão conciliatórios com as brasileiras?

A resposta pode tal vez ser encontrada em sua discussão so bre os esforços dosEU A para "substituir completamenteo mito nacional da 'democracia racial' [... ] pel o mito [norte-americano] segundo o qual todas as sociedades são 'racistas'". Para os autores, este procedimento faz do "conceito de racismo", não uma "ferramenta analítica", mas um "mero instrumento de acusação" dentro de uma lógica, não de pesquisa científica, mas de um julgamento. É apenas a partir de uma numa nota de rodapé que se começa a perceber o que realmente está em jogo para Bourdieu e W acquant (1999: 44, 53):

Q uanto tempo teremos que esperar para ver surgir um livro intitulado Brasil Racista, modelado segundo o cientificamente escandaloso França Racista deum sociól ogo francês mais preocupado com as expectativas do campo do jornal ismo do quecom as complexidades da realidade social?

Estariam el es invocando o B rasil, talvez, como parte de um esforço para defender a honra da F rança? Poderiam estar desmascarando, por antecipação, aqueles que estariam usando o exemplo dos EU A, através de retórica ou metodologia acadêmica, para ameaçar a autoconstrução mítica de seu próprio país como universalista e, por definição, a- ou anti-racista? ${ }^{20} \mathrm{~N}$ ão poderiam el es estar usando - Brasil de forma oportunista para atacar intelectuais, especialmente esquerdistasnosEU A ou afro-norte-americanos (ou, quiçá, mais perto de casa, cidadãos franceses ou resi dentes de origem árabe ou norte-africana), que estariam pondo em risco a sua querida noção de francesidade?

Ao adotar uma postura de vitimização junto com o Brasil nas mãos do imperialismo norte-americano, Bourdieu e Wacquant parecem exibir o mesmo "nacionalismo vangloriante" que os brasileiros defendem quando impedem a autocrítica ao julgar seu país apenas, epositivamente, contra osEU A em termos deraça (C unha, 1998:247). Se o racismo é, por definição, aquilo que se faz nosEU A, então nem a França nem o Brasil podem ser chamados de racistas. Tal gesto é também essencialmente brasil eiro; é o que o sociólogo Florestan Fernandes certa feita definiu como 0 preconceito brasileiro mais profundo: "o preconceito de não ser preconceituoso". Como um informante disse a Robin Sheriff no

\section{0}


Rio: "Não há violência racial no Brasil, nada. Não é como nos Estados Unidos, sabe?" (Sheriff, 1997:409).

Bourdieu e Wacquant conhecem muito pouco sobre a realidade da raça ou do pensamento sobre a raça no Brasil ou EUA para que seu artigo seja útil ou de valia. Na melhor das hipóteses, sua polêmica esclarece o sentimento de dois intelectuais europeus importantes, seu sonho de França, e a distopia que vêem nos "Estados Unidos" (tratados simplisticamente como um monolito). Em resumo, a melhor forma de ver seu artigo é como um grito de frustração de dentro do mundo imperialista do Atlântico Norte, uma polêmica defensiva marcada pela surpreendente hiper-sensibilidade dos autores e pelo sentimento, claramente expressado, de uma honra ferida. ${ }^{21}$ Em sua retórica bombástica, rica em metáforas sexualizadas de processos ilícitos de sedução e penetração, os autores revelam uma falta de confiança e acuidade que gera erros vergonhosos de avaliação - do Brasil, dos Estados Unidos, e da França.

\section{A Dimensão Ausente: Idéias Norte-Americanas de "Raça" e seu "Consumo" no Brasil}

Em sua polêmica, Bourdieu e Wacquant tratam seus adversários de forma agressivamente desdenhosa, especialmente os norte-americanos e os ingleses, ${ }^{22}$ ao mesmo tempo em que criticam o tropismo em direção ao poder exibido por muitos intelectuais nos países dominados. Porém, estes dois intelectuais europeus mostram uma arrogância imperial em seu olhar apressado e desenhoso sobre o debate em torno da "raça" na diáspora africana no Novo Mundo. Emitem opiniões de forma descompromissada sobre o Brasil, apesar de sua ignorância a respeito deste país continental com mais de 170 milhões de habitantes. De acordo com a sua interpretação, os brasileiros indefesos precisam de um defensor estrangeiro em face do ataque dos EUA, justamente porque a troca intelectual "flui apenas em um sentido"; até mesmo as idéias norte-americanas "fora do lugar", lamentam, podem se impor no Brasil (Bourdieu \& Wacquant, 1999:46).

Os autores de "Sobre as Artimanhas da Razão Imperialista" dão peso analítico apenas à produção e circulação transnacional de idéias, enquanto ignoram a dinâmica de "leitura" e "tradução" através das quais as idéias estrangeiras são incorporadas às áreas intelectuais nacionais, cada uma com a sua trajetória histórica, formação cultural, e mitologias sociais próprias. ${ }^{23}$ Seu modelo sim- 
John French

plista de dominação/imposição dos EU A e submissão/cumplicidade subalterna étei mosamente errado, tanto de um ponto de vista empírico, quanto teórico. Ele apaga o processo de apropriação local ao mesmo tempo em que amplamente exagera o poder e influência queas noções produzidas nosE U A têm tido ou podem ter no Brasil. Em resumo, fetichizam a origem "estrangeira" dasidéias (ela mesma questionável), enquanto descrevem o processo detrocatransnacional como inerentemente de mão única. Pior detudo, seu chamado à resistência é comprometido pela sua própria prefe rência para se refugiarem por detrás de tênues barricadas nacionalistas, em vez de promoverem um debate intelectual e político transnacional sério.

D e fato, pesquisadores e militantes brasileiros, hoje, não aderem ao modelo racial postulado por Bourdieu e Wacquant, mesmo quando tenham sido formados nos EU A, ou tenham recebido bolsas da Ford Foundation. A publicação de 0 rfeu e o Poder em 1994 também não levou acadêmicos e militantes negros brasileiros a se submeterem a "leituras" norte-americanas de raça. Em vez disso, ajudou a cristalizar uma convicção brasileira, que passa pela diversidade em termos de nacionalidade de origem, raça e sexo, que as diferenças são mais importantes do que as semel hanças nestemomento da discussão comparativista (o vigoroso debate pode ser acompanhado em Bairros, 1996; Fry, 1995a, 1995b; H anchard, 1994a, 1996a, 1996b, 1996c; Silva, D ., 1998; C unha, 1998; Segato, 1998). Sea tônica nos an os 80 era a ênfasena similaridade, a literatura mais recente sublinha as especificidades nacionais e até mesmo a originalidade dentro do contexto diaspórico. Representa, poderíamos dizer, a consolidação de "uma problemática de relações raciais propriamente brasileira, [que começou a surgir na década de 50, e] que se distancia do modelo comparativista e contrastivo herdado de Gilberto Freyre" nos anos 30 (ao qual Bourdieu eW acquant ainda estão presos, com o seu uso da dicotomia entre Brasil eEU A) (G uimarães, 1999:91) O ndeseencaixa 0 rfeu eo Poder, com seu contrasteEU A/B rasil, no renascimento atual da literatura sobre raça, cultura, nação e poder no Brasil?

A idéia da diáspora africana representou, em si mesma, um avanço conceitual decisivo, que sublinhou o pano de fundo comum da escravidão racial a suas ideologias anti-negras de superioridade branca sem, contudo, reduzir a história subseqüente dos povos descendentes de africanos apenas à sua vitimização pela subordinação racial. "A civilização e negritude africanas influenciam-se mutuamente", como observa a antropóloga Rita Segato,

\section{2}


Passosem Falso da Razão Antiimperialista...

"e o lugar da África e o lugar da raça nas nações do N ovo M undo estão mutual mente banhadas em uma articulação complexa [que é] extremamentedifícil de ser desembaraçada... [masque] varia de acordo com o quadro nacional" (Segato, 1998:130). "N ossa negritude comum" dentro do Novo M undo, observa Denise Silva, "tem sido atravessada por efeitos particulares da condição nacional, de sexo e classe. A escravidão e o colonialismo formaram o chão histórico... [mas] em cada caso, é construído... de acordo com condições históricas esociais deum dado espaço social multiracial... [e] os desdobramentos históricos e discursivos específicos que informam as estratégias de subordinação racial" (Silva, D ., 1998:230). N as palavras dela, há muitas subjetividades negras dentro da diáspora africana no $\mathrm{N}$ ovo M undo que não podem ser facilmente tidas como análogas ao caso norte-americano. ${ }^{24}$

"É importante enfatizar a diferença de como o sistema racial brasileiro foi constituído", argumenta a antropóloga O lívia Cunha (1998:247), porque

[... os casos paradigmáticos do Brasil e dos Estado U nidos mostram que as modalidades específicas de exclusão eas concepções étnicas estão profundamente relacionadas [...] [à] variedade de operações cognitivas de discriminação e exclusão que fundimos no nome comum de racismo [e que] estão profundamente en raizadas nas estruturas de relacionamentos desenvolvidas através de uma história nacional particular. (Segato, 1998:130, 135)

Resumindo, "o racismo no Brasil, independente do quanto pode ser proveitoso localizá-lo em continuidades globais, permanece culturalmente distinto" (Sheriff, 1997:42).

A dificuldade apresentada pela comparação EU A/Brasil, sugere $D$ enise Silva, reside no fato de que

As pressuposições que alimentam a análise contemporânea da subordinação racial no Brasil [...] [assim como] as categorias empregadas no estudo das sociedades multirraciais surgiram [primeiramente] como uma tentativa de lidar com uma condição particular de multirracialidade, os Estados U nidos [...]. Q uando estudiosos começaram a dar aten ção às similaridades entreestas duas sociedades, [...] tenderam a interpretar a subordinação racial no Brasil como uma mera variação no modelo que[...] antes de mais nada representava os pontos de contraste [...] [Assim,] as peculiaridades da raça no Brasil aparecem como uma questão de grau, como uma realização menos desenvolvida de uma construção de raça, que tem suas premissas em uma visão da sociedade como composta de gruposraciaisclaramentedistinguíveis. (Silva, D ., 1998:204, 206-207) 
John French

Assim, há um sério erro, argumenta Silva, nos argumentos de al guns dos anal istas norte-americanos menos cuidadosos, tais como H oward W inant, o "principal interlocutor" de $\mathrm{H}$ anchard (H anchard, 1994a:ix). A pesar de teoricamente aprovar uma abordagem social construcionista para a questão da raça, W innant ainda baseia-se em seus escritos em uma noção, típica dos EU A,

[...] dequea diferença racial é(como o sexo) um substrato pré-social, sobre o qual relações sociais são desenvolvidas. 0 que se perde [...] é que a importância política da raça não reside na interpretação e imposição de significados sobre estas diferen ças [fenotípicas], mas na própria produção de tais diferenças como sendo raciais (Silva, D ., 1998:212). ${ }^{25}$

Assim, W inant trata a raça como "um fato que passa por fronteiras contextuais" ao mesmo tempo querevela "afal ta defrontei ras sociais e históricas" para sua "noção de formação racial" (Segato, 1998:132). ${ }^{26}$

"I ronicamente, o esforço problemático de $\mathrm{H}$ anchard para responder a questão também fornece sugestões importantes para abordar 0 assunto", D eniseda Silva argumenta, apesar dereproduzir, ao menos parcialmente, a "universalidade etnocêntrica de W inant". Q uando $\mathrm{H}$ anchard defende que a ideologia da democracia racial tem "neutralizado a identificação racial" e produzido a "ausência de uma consciência racial entre os afro-brasileiros", ela continua, ele se esquece que a subjetividade afro-norte-americana (um termo que ela prefere à "consciência racial") "surgiu de uma condição particular de subordinação racial. Conseqüentemente, esta construção particular da subjetividade negra sub-repticiamente coloniza sua análise da mobilização racial no Brasil... [N o entanto] a articulação específica de raça, nação, esexo que caracteriza a construção brasil eira de raça", ela reitera, "não é melhor ou pior do queaquela predominantenos Estados U nidos; éapenas diferente. E esta diferença deve ser o ponto de partida da análise da política racial no Brasil" (Silva, D ., 1998: 222-3).

A intrigantecrítica da autora também refletea natureza dual da troca que ocorre entre as diferentes realidades nacionais dentro da diáspora. A pesar de ser ela mesma uma militante negra inspirada pelas luta dos afro-norte-americanos, esta estudante brasileira de pós-graduação em sociologia na U niversidade de Pittsburgh observa que "ser negro aqui [nos Estados U nidos] deu-mea vantagem de poder me ver pel os olhos de 'O utros' - negros e brancos neste caso. Pareceu ter-me ajudado a diminuir a distância e perceber que eu e meus companheiros de militância somos mais 'brasi-

\section{4}


Passosem Falso da Razão Antiimperialista...

leiros negros' do que éramos levados a crer no Brasil" (ibidem: 225). Esta experiência de alteridade é paral ela às observações de uma jovem estudiosa afro-norte-americana da história do Brasil, Kim Butler, em seu livro inovador Liberdades D adas, Liberdades Conquistadas: Afro-Brasileiros na São Paulo e Salvador Pós-Abolicionistas. O contato dosEU A com o Brasil, ela insiste, deixa "claro que, o que inicialmente ao ol hos norte-americanos aparentava ser uma grande população negra", era, de fato, um grupo heterogêneo de várias comunidades pequenas. "Apesar de dividirem uma he rança de escravidão e uma ligação com o continente africano", ela continua, "não havia nenhuma identidade étnica unificadora que pudessecriar um verdadeira comunidade dentro dessegrandeediverso grupo demográfico... [apesar de sua] existência freqüentemente parecer óbvia quando vista pelo prisma da experiência norte-americana" (Butler, 1998:218).

Como os brasileiros, Butler conclui que a "negritude" "não surge intrinsecamente da existência de uma herança africana, mas é condicionada e model ada pela dinâmica histórica e específica de cada sociedade escravocrata... [e que] a etnicidade da 'negritude,' uma combinação de traços somáticos e de uma herança cultural africana, não énem fixa nem constante na diáspora africana" (ibidem: 218, 50, 7). Contextualizando explicitamente seu trabalho dentro do quehá de comum na diáspora africana, a investigação de Butler da experiência afro-brasileira desde a A bolição também revela a utilidade limitada das comparações nacionais. Ao comparar as diferentes trajetórias de povos descendentes de africanos nas cidade de Salvador e São Paulo, Butler ilustra a riqueza da diversidade mesmo dentro de um único espaço nacional: "À medida que as diferenças regionais são exploradas, a etnicidade [negra] aparece como um fenômeno fluido, tanto em resposta a condições sóciopolíticas, como seu resultado" (ibidem: 129)

Se a situação brasileira em termos de desigualdade racial e "dominação etno-racial" é bem pior do que admitem Bourdieu e W acquant, deve-se também enfatizar que os trabalhos que deploram, como 0 rfeu eo Poder, não têm sido de maneira al guma nefastos em seu impacto na comunidade intelectual brasileira. Tais autores ficariam felizes, ou, talvez, reassegurados a respeito da ineficiência do imperialismo cultural em questões de raça, assi m como em relação à sofisticação e clareza com as quais sas vítimas, agentese cúmplices brasilei ros formularam, em termos bem mais precisose convincentes, uma ampla crítica da "universal idade etnocêntrica" na discussão conceitual da raça. Se honestos, eles poderiam até fi- 
John French

car impressionados pela publicação destes artigos em ingl ês eapreciar o diálogo, respeitoso e de alto nível, que tem ocorrido sobre estetema vital. Poderiam até notar queéR ita Segato, da U niversidade de Braślia, e não $\mathrm{M}$ ichael $\mathrm{H}$ anchard, que mais severamente denuncia "a existência de uma atitude e sentimento racistas virulentos contra pessoas de cor negra" no Brasil (Segato, 1998: 148).

Bourdieu eW acquant, no entanto, não estão no mesmo terreno que os atuais estudiosos de raça e cor no B rasil, sejam el es brasileiros, norte-americanos ou europeus. Indulgindo em seu recalque contra os EU A, os autores de "Sobre as Artimanhas da R azão Imperialista" distorceram o trabalho de estudiosos sérios como $M$ ichael $\mathrm{H}$ anchard e se refugiaram na asserção fácil demais, de que a palavra "raça" não tem relevância no contexto brasileiro, porque ela teria que significar "raça" como éentendida nos EU A! Pior ain$\mathrm{da}$, el es adotaram, em nome de uma solidariedade antiimperialista, uma postura acrítica de solidariedade com a mitologia nacional brasileira de uma sociedade racial mente igualitária e assim se distanciaram do projeto anti-racista queunetodosos participantes do atual debate (Burdick, 1998; T wine, 1997; Sheriff, 1997). Sua surpreendente falta de sensibilidade para as questões de raça reflete uma recusa implícita ou, ao menos, a minimização, do processo histórico de subalternização ao qual os africanose seus descendentes têm sido submetidos no Brasil, Estados U nidos e França.

A força motriz e a urgência do presente debate sobre raça e racismo no B rasil vêm de uma busca comum para se encontrar as armas mais eficientes a serem usadas na luta anti-racista. 0 desdobramento desta discussão é, assim, político no melhor sentido da pal avra e reflete, como explica Cunha, a mudança no terreno político brasileiro nos vinte anos desde a fundação do $\mathrm{M}$ ovimento $\mathrm{Ne}$ gro U nificado (M N U ). A questão central hoje, sugere, é "quetipo delinguagem deve ser utilizada para trazer visibilidadeà discriminação racial e ao racismo que existem na sociedade brasileira?" (C unha, 1998: 240). Este objetivo anti-racista também define 0 campo para o diálogo transnacional. Segato explica que a comparação com os EU A pode ser usada "para contribuir para a formulação de uma política adequada para a luta contra o racismo no Brasil" (Segato 1998: 148, 137). E D enise daSilva, apesar de sua ênfasenas diferenças, insisteque, como "a raça tem sido a base discursiva comum para [a] subordinação mundial dos não-brancos", a comparação transnacional éessencial para nossos esforços comuns com vistas a "formular contradiscursos insurgentes, que serão, ao

\section{6}


mesmo tempo, intervenções teóricas e políticas verdadeiramente não-etnocêntricas" (Silva, D .,1998: 230).

0 terreno prático eideológico sobreo qual aluta anti-racista sedesdobrano Brasil, como notaSilva, éaquele de "uma sociedade multirracial onde manifestações de 'preconceito de raça' e atos de 'discriminação racial,' e grandes níveis de desigualdade entre negros e brancos coexistem com uma construção da raça que rejeita a separação ecelebra a harmonia racial" (ibi dem: 223). Seguindo Pe ter Fry (1995), C unha chama a atenção para o risco de se reduzir "a democracia racial" a um mero mito, entendido como sinônimo de fraude (Cunha 1998: 225-6; cf. também Sheriff, 1997: 435-6). Seja em relação aos EU A ou ao Brasil, as dinâmicas das mitologias sociais são bem mais complexas do que a mera oposição de uma "mentira" à "verdade". Essa complexidadeésugerida pela tentativa de Segato de relacionar as mitologias raciais e nacionais nas duas sociedades: "Se, de cima para baixo, o paradigma étnico norte-americano é baseado na separação, dentro do mito compartiIhado por todas as raças da recompensa deacordo com o esforço eo mérito, no B rasil o paradigma étnico ébaseado na incorporação do outro, na inclusão como seu forte tema-chave, e o mito aqui é o mito de um povo se interrelacionando independentemente da cor" (Segato, 1998: 137).

M uitos brasileiros, nota Robin Sheriff, temem que os movimentos negros criarão separações entre os brasileiros assim como ocorre nas relações "raciais" no estilo norte-americano. Com efeito, ela descobriu que os militantes negros mais freqüentemente "invocam o sonho, não de um movimento composto unicamente por pessoas de cor, mas um movimento dirigido contra todas as formas de discriminação" (Sheriff, 1997: 429). D e fato, M ichael $\mathrm{H}$ anchard também relata que a criação de uma sociedadenegra alternativa, como nosEstados U nidos, vai contra os sentimentos expressados pelos militantes negros entrevistados: "N inguém expressou interesseem ser partede um partido político, igreja ou outra instituição a nível nacional que fosse racialmente específica" (H anchard, 1994a: 84-82). Poderia ser sugerido, talvez, quealuta dos movimentos negros no Brasil tem em seu centro a exigência articulada no manifesto fundador do M NU em 1978 - de que o B rasil seja uma verdadeira democracia racial, ao invés da rejeição de uma democracia racial per se. Sua esperança para a sociedade brasileira, como coloca Sheriff, é "simplesmente de voltá-la para seu próprio sonho" (Sheriff, 1997: 431). 
John French

0 movimento da "C onsciência N egra", renascido como parte integrante da grande revolta democrática contra o regime militar no fim da década de 70, na real idade adotou discursose símboIos estrangeiros, tanto dosEU A quanto daÁfrica (uma prática que $\mathrm{M}$ ichael $\mathrm{H}$ anchard critica em $\mathrm{O}$ rfeu e o Poder). 0 movimento fez uso do gesto radicalmente iconoclasta de asseverar que a raça e 0 racismo no Brasil são como nos EU A, mas este discurso nunca deveria ser entendido, como sugerem Bourdieu e W acquant, como uma simples "imitação" ou submi ssão a um produto "estrangeiro" importado. 0 mínimo que se pode dizer é que o caso das idéias norte-americanas de "raça" e sua apropriação no Brasil demonstram a capaciadade dos intelectuais subalternos de subverter as idéias estrangeiras.

Como uma sociedade periférica à margem do mundo do Atlântico N orte, os brasilei ros têm há muito tempo vivivenciado a importação por atacado de idéias da metrópole e a dependência cultural tem gerado um intenso debate sobreo papel detais “idéias fora do lugar" (Schwarz, 1992). Estas questões são fundamentais: as idéias têm de fato um lugar? E que papel, se é que ele existe, as idéias "importadas" desempenham dentro da sociedadebrasilei ra? Representam elas desvios nocivos que devem ser combatidos, ou uma pura ornamentação que é irrelevante? Exercem um papel positivo ou prejudicial? Essa longa controvérsia tem sido concentrada na importação, não de idéias norte-americanas, mas européias, como o liberalismo, por exemplo. ${ }^{27} 0$ impacto limitado de produtos importados do imperialismo cultural fancês e inglês no século XIX também foi demonstrado pelo surgimento do "racismo científico", como nos escritos do francês G obineau, que baseou sua "ciência" fraudulenta em parteem seu serviço diplomático no Brasil (Raeders, 1988). Esta doutrina da superioridade européia era amplamente aceita por intelectuais da classe al ta brasileira, mas ao fazer isso, como mostraram Skidmore (1993) e Costa (1995), tais intelectuais descartavam princípios subjacentes fundamentais da ortodoxia racista que pretendiam abraçar.

A adoção de idéias raciais dos EU A por intel ectuais brasileiros e militantes negros foi também marcada, com o decorrer do tempo, pelas próprias "Ieituras" que fizeram destas "idéias fora do lugar". O militante J oel Rufino dos Santos recentemente chamou a aten ção para as dificuldades envolvidas no uso, pelo movimento negro, de uma "idéia deraça do século XVIII" para alcançar objetivos anti-racistas. 0 "negro" no Brasil, ele propõe, seguindo Guerreiro Ramos, deveria, pelo contrário, ser visto como

\section{8}


Passosem Falso da Razão Antiimperialista...

[...] uma configuração social, um lugar que pode ser ocupado mesmo por não negros (assi im como o lugar do branco pode ser ocupado por um preto ou mulato). C omo se descreve esse lugar? As coordenadas para fixar o negro como lugar seriam: o fenótipo (crioulo), a condição social (pobre), o patrimônio cultural (popular), a origem histórica (ascendência africana) eidentidade (autod efinição ed efinição pel o outro). A coordenada mais fraca éo fenótipo, uma vez que a maioria da nossa população tende para o escuro. Brasil ei ro é, como se deduz, o mel hor sinônimo de negro; e branco, um sinônimo de não brasileiro. (O liveira, 1995)

"[A]presentar o problema do negro como o problema do Brasil”, continua, éa maneira mais radical de lutar contra o racismo. "O problemado negro", insisteo militanteClovisM oura, "faz parte, pois, do problema nacional... [cuja solução] passa pela sua integração social, econômica, cultural e psicológica ao seio da nação ea sua desmarginalização como cidadão" (M oura, 1994: 234). $\mathrm{O}$ veterano militanteH amilton $\mathrm{C}$ ardoso observa deforma similar: “O problema crucial encontra-sena definição do próprio modo de ser do brasileiro que, hoje, por mais branco que possa ser, quando visto pel o europeu (o verdadei ro branco, o puro, o legítimo, como se costuma dizer ironicamente entre negros), é visto como 'um branco fora do lugar'". I sso éo que os "ativistas, militantes e intelectuais negros" querem dizer, prossegue, quando notam que "todo branco [brasileiro] tem um pé na senzala" (C ardoso, 1987: 89; para a construção brasileira da brancura cf. Segato, 1998: 136, 146-7; Sheriff, 1997, 321; T wine, 1997: 71). Resolver o problema do racismo no Brasil, disse uma vez uma líder do M N U, Lélia G onzales, seria resolver "a neurose cultural brasileira... Racismo? N o Brasil? I sso é coisa de americano!"

Apesar de serem freqüentemente criticados como "não-brasileiros", os militantes e movimentos de consciência negra têm demonstrado uma grande habilidade para incorporar idéias vindas defora a uma visão de mundo brasil leira que correspondeàquilo de melhor que o país sonhaser. Ainda queimportações do estrangeiro muitas vezes tenham motivado uma reação defensiva enacionalista no Brasil, a resposta mais saudável para a dependência cultural brasileira tem sido "consumir" confiantemente idéias estrangei ras e incorporá-las a produções originais brasileiras. Chegamos, assim, ao el ogio da antropofagia, que data dos anos 20, como a metáfora central para a conceitualização do el o entre o local e o global em um mundo cada vez mais fortemente, ainda que desigualmente, integrado (J ohnson, 1987; Santiago, 1978). ${ }^{28}$ 
John French

\section{Conclusão}

A trajetória histórica dos povos descendentes deafricanos no Brasil e nos Estados U nidos tem atraído gerações de tal entosos estudiosos nos últimos setenta anos, produzindo um corpus de pesquisa nas ciências humanas de al ta qualidade e de forma contínua, que corta várias disciplinas (Barcelos, 1991; Andrews, 1997; Bastide, 1974; Fontaine, 1980; French, 2000; Parker, 1978; Russell-Wood, 1982). A última década testemunhou uma emocionante nova fase de engajamento, tanto no Brasil quanto nosEU A, com os brasileiros exercendo um papel cada vez mais ativo junto com intelectuais de origem africana nos dois países. ${ }^{29} \mathrm{M}$ ais importante ainda, este diálogo transnacional sem precedentes, que Bourdieu e W acquant simplesmente não conseguem ver, é bem menos desigual do que no passado; na verdade, um dos desdobramentos mais proveitosos e provocadores foi a emergência de uma articulação brasileira e claramente enunciada da dialética entre similaridades e diferenças entre Brasil e Estados U nidos, especialmente em relação a questões de identidade e subjetividade (Cunha, 1998; Silva, D ., 1999, Segato, 1998; G uimarães 1999).

A hegemonia global das "idéias norte-americanas" hoje, Bourdieu e W acquant observam com razão, não é, na realidade, "natural", apesar do predomínio contemporâneo de metáforas de mercado, e o volume e velocidade crescentes da troca de idéias e produtos culturais não altera a assimetria entre nações. Eles também não estão errados em ver um desejo por parte dos EU A de se tornarem a autoproclamada "única superpotência", para alcançar, dentro do campo cultural eintelectual, o mesmo predomínio, quiçá domínio, já al cançados nas áreas econômica, di plomática e militar. D e fato, a própria predominância dos EU A serve como um azedo contraste para seus rivais, potências imperialistas menores como a França, que estão encontrando dificuldades crescentes para manter seu "lugar ao sol" dentro do terreno do capitalismo global. Todavia, o uso mal fundamentado do exemplo brasileiro por parte de Bourdieu eW acquant, motivado por suas angústias e sensibilidades, contribui muito pouco para o conteúdo do presente debate. Seria muito triste, no entanto, se leitores não especializados, por respeito às muitas contribuições intel ectuais de Pierre Bourdieu, fossem desencorajados de participar deste promissor diálogo transnacional sobre o Brasil, no qual novas questões sobre um vel ho tópico estão sendo formuladas, dentro de um quadro comum de luta contra o racismo e a desigual dade.

\section{0}


Passosem F also da Razão Anti imperialista...

Em um mundo marcado pela regressão social e dominado pelas ocupações imperiais da OTAN , Bourdieu eW acquant deveriam lembrar-se de que o sucesso das lutas populares só pode ser alcançado através de uma investida abrangente contra as desigualdades estruturais e todo tipo de violência, esteja ela relacionada aos sexos, classes sociais ou grupos raciais ou étnicos. Para que selevea cabo estaluta tran snacional énecessário queintelectuais emilitantes mantenham uma visão vigilantemente autocrítica das deficiências de sua própria sociedade. Ao mesmo tempo, intelectuais com um posicionamento crítico devem manter uma postura de respeito e solidariedade (que não impede 0 desacordo e 0 debate) que evite 0 des-entendimento teimoso e ataques mal fundamentados contra al iados potenciais em outros países.

\section{N otas}

1. O título em francês é "Sur les Ruses de la Raison Imperialiste", Actes de la Recherché en Sciences Sociales, 121-122, março 1998, pp. 109-118.

2. Em uma capitulação inconsciente à arrogância imperial dosEU A, Bourdieu eW acquant u sam o termo "americano" em referência aosE stados U nidos, apesar deosresidentes dos países de todo o $\mathrm{N}$ ovo $\mathrm{M}$ undo serem de fato "americanos". Esta é uma questão al go delicada na América $L$ atina, ondecidadãos dosEU A são freqüentemente chamados de norte-americanos. $\mathrm{N}$ a fal ta de uma alternativa melhor, seguirei esta prática latino-americana, mesmo em detrimento das especificidades nacionais do Canadá.

3. 0 antropólogo Peter Fry refutou recentemente, com al guma irritação, a afirmação de Bourdieu e Wacquant segundo a qual a Rockefeller Foundation "estabeleceu como condição para a liberação de verbas que o grupo de pesquisa [sobre raça eetnicidade em sua instituição, a U niversidadeF ederal do Rio deJ aneiro] fosse selecionado de acordo com critérios de ação afirmativa [norte] americanos". A fundação em questão, continua, "na realidade não impôsnenhuma condição para financiar o programa de raça e entnicidade, quetrouxe estudiosos do mundo inteiro para nossa universidade (incluindo Löic W acquant). N este caso, então, ao menos uma universidade brasileirafoi financiada por uma famosa fundação [norte] americana para colocar a experiência [norte] americana em seu devido lugar, como nada mais do que uma forma historicamente específica de se construir a raça, institucional izar o racismo e em seguida combatê-lo" (Fry, 2000:112-13).

4. Para discutir o trabalho de $\mathrm{H}$ anchard, utilizarei resenhas relevantes de 0 rfeu eP oder escritas por brasilianistas (o cientista político M ichael M itchell, os historiadores Kim Butler e Richard G raham, e o antropólogo John Burdick). Farei uso, também, de duas resenhas escritas por especialists em outras áreas (Alejandro de la Fuente, um recente Ph.D que estuda a questão racial em C uba, e o sociólogo H oward W inant). Finalmente, aproveitarei as discussões e artigos recentes sobre $\mathrm{H}$ anchard tanto de sociólogos brasileiros (Luiza Bairros, D enise Ferreira da Silva, e Antonio Sérgio Alfre- 


\section{John French}

do G uimarães) quanto de antropólogos (Peter Fry, Rita Segato, e 0 livia G omes da Cunha).

5. Richard G raham (1995) nota que "as rel ações de poder entre raças no Brasil têm por muito tempo atraído a aten ção de observadores estrangeiros [...] até mesmo quando estes escritores não reconheciam que o que estava em jogo eram questões de poder" (como no caso de Bourdieu e W acquant).

6. Em sua revisão bibliográfica dos estudos latinos-americanos, Pierre-M ichel Fontaine notou que "os estudos afro-brasileiros têm ocupado um espaço crescente" e que "não épor acaso que boa parte dos trabal hos mais interessantes foi etem sido feita no ou sobre o Brasil, apesar dos obstáculos lá encontrados" (Fontaine, 1980:208).

7. D evido à sua própria natureza, as comparações não têm razão de ser se os objetos comparados são exatamente os mesmos ou completamente diferentes (French, M örner eV iñuela, 1982). Para uma apresentação esquemática das semelhanças ediferençasentreas experiências dospovos descendentes de africanosnos EU A eno B rasil, cf. French (2001) [http://www.duke.edu/web/las].

8. Cf. Cunha (1998), para a lógica política por detrás desta tática do movimento.

9. Para trabalhos mais recentes nessa linha, ver Telles $(1992,1993,1994)$, Lovell (1994), Reichmann (1999).

10. Para uma crítica das idéias "primordialistas", cf. o estimulante artigo dos antropólogosJ ohn eJ ean Comaroff (1992) quetambém delineiam uma discussão teórica muito proveitosa sobre a origem das "raças" ou etnias, assim como a emergência e subseqüente transformação da consciência "racial" ou étnica.

11. H anchard se destaca em rel ação a outros estudiosos e militantes precisamente por causa de sua recusa em equacionar a sobrevivência africana ou resistência cultural negracom a mobilização política contra o racismo ou a desiguladade racial. Sua postura em relação à cultura e religiosidade afro-brasileiras gerou discordâncias fortes mas proveitosas por parteoutrosestudiosos (Burdick, 1998; Butler, 1998; Segato, 1998). Além disso, $\mathrm{H}$ anchard também se move dentro dos debates nos movimentos da "Consciência N egra" em torno do papel do "culturalismo" como estratégia do movimento.

12. U m sentimento de al ien ação pode acompanhar algumas variantes da militância negra brasileira, como em um artigo de 1992, publicado em inglês por doislíderes do M N U . 0 racismo no Brasil, escrevem, "permeia todas as áreas da vida nacional [...] com tanto sucesso [...] que a maioria da população brasileira tem dificuldade para identificar o racismo, quando ele acontece [...] Porque ele está tão profundamente enraizado no dia-a-dia de nossas vidas, o Brasil é um dos poucos lugares do mundo em que podemos dizer que há uma aceitação do racismo por parte daquel es que sofrem com ele." D esta maneira, o racismo opera no Brasil não apenas através "da dominação da maioria da população por uma minoria, mastambém pela aceitação ecolaboração tácitas em sua continuação, com mínimos protestos por parte daquela maioria" (C aetano e Cunha, 1992:86).

13. Para militantes brasileiros negros, o processo de "conscientização" éum desafio para os indivíduos descendentes de africanos para "assumir sua negritude", uma terminologia característica quando comparada ao caso norte-americano. Florestan Fernan-

\section{2}




\section{Passosem F also da Razão Antiimperialista...}

des (1989) discute o negro assumido dentro da classe média em relação ao seu oposto: o negro de alma branca. Cf. também a análise de Sheriff (1997b:418-427).

14. $O$ antropólogo John Burdick (1995) questionou o fato de $\mathrm{H}$ anchard "basear-se quase exclusivamente no discurso oral de líderes", sem observações vindas de baixo, de participantes que não eram líderes, ou que estavam fora do movimento, "afro-brasileiros que, por qualquer razão, decidiram manter distância dele". N o entanto, o foco exclusivo de $\mathrm{H}$ anchard em militantes negros (negros assumidos) de fato revela os supreendentes dilemas do movimento com uma claridade persuasiva. 0 rico potencial de uma abordagem dos não-militantes é bem revelado na fascinante monografia de 1998 de Burdick sobre as mulheres no Rio de Janeiro, assim como a provocativa exposição, ainda que menos el aborada, de entrevistas sobre raça que ela conduziu no interior do Rio de Janeiro (T wine 1998). Sheriff (1997a) fornece uma explicação sensata de discursossobre raça e cor por militantesenão-militantes, brancos e não-brancos, tanto pobres quanto da classe média do R io de Janeiro. L amento apenas que $H$ anchard não tenha explorado mais completamente seu material de entrevistas e o combinado com uma anál ise mais extensiva da produção intel ectual do movimento. Sobre este último ponto, $\mathrm{H}$ anchard foi criticado por um membro do M N U por subestimar a capacidade própria do movimento negro brasileiro "para elaborações práticas e teóricas". C omo um exemplo, Bairrosmenciona o erro, por parte deH anchard, deaplicar uma teoria de hegemonia baseada em G ramsci ao caso brasileiro, sem "dar atenção à sua configuração dentro do próprio movimento negro" (Bairros, 1996:178, 180) em que era, como Cunha (1998:229) observa, a principal moeda corrente da discussão do movimento na década de 70 (assim como na esquerda como um todo).

15. D eve-se enfatizar que 0 rfeu eo P oder não éuma história enciclopédica dos movimentos de consciência negra desde 1945 (uma continuação do valioso estudo de Butler dos movimentos negros em São Paulo até a década de 1940 [1998] se faz altamente necessária, eainda esperamos o final do estudo de Anani D zi edzenyo sobre o importante militante do M ovimento $\mathrm{N}$ egro, Abdias do $\mathrm{N}$ ascimento [D ziedzenyo, 1991]). 0 livro deH anchard também não éum exercício rigoroso de como construir um modelo de análise social científica por meio da formulação de hipóteses e seu teste. Em vez disso, éum sugestivo conjunto deensai osinter-relacionados, motivados por preocupações teóricas, queé "rico em idéias e cheio de detal hes surpreendentes" sobre o mundo dos movimentos negros no Brasil (Graham, 1995). Ainda queH anchard tenha sido criticado por não conseguir fornecer um estudo comparativo sistemático da evolução dos movimentos negros em São Paulo e no R io de Janeiro (Fuente, 1995), Kim Butler observa, com acerto, que 0 rfeu e o Poder não é “um relato estritamente histórico, nem pretendeser" (Butler, 1996). C omo M itchell (1995) nota, eleé "antes de mais nada, uma obra teórica" na qual encontramos "menos atenção aos detalhes" do que nos estudos históricos revisionistas, tal como o excelente, e merecidamente influente, estudo de G eorge R eid Andrews, 0 sB rancose os N egros em São Paulo, Brasil, 1888-1988 (1991; 1998). Com efeito, o livro de H anchard não se "propõe a ser um texto definitivo, mas, ao contrário, a gerar novos debates e abordagens meto dológicas à história política afro-brasileira" (Butler, 1996) e as evidências são usadas primordialmente para ilustrar seus argumentos teóricos e conceituais (M itchell, 


\section{John French}

1995). N este sentido, a monografia de $H$ anchard não oferece uma contextual ização profunda do movimento da consciência negra no Brasil, mas, em vez disso, um criativo esboço de alguns de seus dilemas principais.

16. Bourdieu e Wacquant demonstram uma ingenuidade considerável ao selecionar 0 $\mathrm{N}$ em N egro nem B ranco, de Carl D egler, como seu "estudo clássico". Ainda queútil, especialmente para norte-americanos, o livro é, em grande parte, carente deoriginalidade e consiste quase que total mente em uma explicação de resultados da pesquisa de campo real izada por estudiosos brasileiros, norte-americanos e franceses na década de 50. A importância do livro de $D$ egler, com efeito, residemenos naquilo que revela sobre o Brasil do que naquilo que mostra sobre as mudanças no campo intelectual dos EU A entrea época de Frank Tannenbaum nosfins dos anos 40, ea revolução do M ovimento dos $D$ ireitos C ivis nosanos 60.0 novo prefácio à edição de 1986 forneceexemplos adicionais das guinadas ideológicas que ocorreram desde aquela época.

17. A existência de preconceito e discriminação racial no B rasil (agora chamados de racismo ao estilo brasileiro) tem, na realidade, sido um consenso entre os estudiosos, que data dos clássicos estudos patrocinados pela U N ESC 0 na década de 50 , sejam eles os brasilei ros como F lorestan Fernandes, Thales de Azevedo, 0 racy $\mathrm{N}$ ogueira, ou Luis C osta Pinto, ou os norte-americanos como C harles W agley e $\mathrm{M}$ arvin $\mathrm{H}$ arris, ou ainda o francês Roger Bastide. 0 s resultados da pesquisa acadêmica, como recentemente observou Andrews, deixam claro que "desigual dade, preconceito ediscriminação raciais são fatos sociais que estão profundamente inscritos na vida brasileira" (Andrews, 1997:25).

18. D uas décadas depois, o historiador afro-norte-americano Leslie R out atacou vigorosamente "a farsa construída em torno das relações raciais no Brasil" por autores, em sua maioria brancos enorte-americanos, na primeira metade do século XX, quando apresentavam "a situação racial brasil leira como relativamenteparadisíaca [...] deforma a exteriorizar sua cólera contra uns Estados U nidos da A mérica segregados", especialmente "a propensão dos brancos sulistas a linchar e queimar". I sto representou, conclui, "a construção de uma fantasia que teria efeitos nocivos para o estudo da história brasil eira", por subestimar o estilo brasileiro de racismo. Foi, ele esperava, um "exemplo claro do tipo de desonestidade intelectual que historiadores [esociólogos] do futuro deveriam escrupul osamente evitar" (R out, 1973: 485-6, 488). Esse uso do Brasil como uma arma no campo dos EUA era também comum entre os afro-norte-americanos em seu contato com o Brasil neste século (H ellwig, 1992). A pesar de não explicitados, os rel atos de visitantes norte-americanos nesta coleção, tanto críticos quanto laudatórios, demonstram uma percepção nítida das semel hanças e das diferenças entre as duas realidades raciais.

19. O bservadores freqüentemente tomam "a falta de pronunciamentos sobre o racismo no Brasil", nota Robin Sheriff, "como uma evidência prima facie de que o preconceito ediscriminação raciais, como um conjunto de problemssociaise/ ou políticos, não são significantes o suficiente para gerar discussões". E oscomentários críticos de norte-americanos sobre o racismo no B rasil são ignorados por esses mesmos observadores por serem "julgamentos etnocêntricos, feitos porque os [norte] americanos são tão obsecados com seu próprio dilema, que não conseguem entender que tal dilema não existe para os brasileiros" (Sheriff, 1997a:126). Sua detalhada e sensata análise

\section{4}




\section{Passosem F also da Razão Antiimperialista...}

dos múltiplos discursos (e silêncios) sobre a questão racial no Rio oferece uma resposta bem-vinda a estas defesas agora já can sativas.

20. Podemos nos lembrar aqui da análise semiótica de R oland Barthes da foto na capa da revista Paris M atch oferecida a ele por seu barbeiro. Ela mostrava um jovem negro, em um uniforme militar francês, provavel mente saudando a bandeira nacional. É claro, escreveB arthes, o que isto deveria significar para o leitor francês: "queaF rança é um grande Império, que todos os seus filhos, sem distinção de cor, fiel mente servem à sua bandeira, equenão há melhor resposta a [seus] detratores [...] do queo fervor demonstrado por este negro" (Barthes, 1972:116).

21. Bourdieu eW acquant descrevem, em várias passagens, a humilhação envolvida no processo de "dominação simbólica" da Europa pelos Estados U nidos. Afinal de contas, assinalam, muitos dos produtos de exportação dos EU A, denunciados por eles, foram, em sua origem, "tomados de empréstimo" dos europeus, que "agora os recebem como as mais avan çadasformas deteoria". E esteerro deinterpretação, continuam, está agora "em vias de ser imposto em sua forma [distorcida norte-] americana aos próprios europeus" (Bourdieu \& W acquant, 1999:53, 43).

22. Bourdieu e $W$ acquant querem evitar o debate e não querem ser incomodados por idéias das quais discordam. Em vez disso, procuram desqualificar automaticamente visões "incorretas" baseando-se em sua nação de origem (apesar de reconhecerem queesteéum assunto confuso). 0 pior detudo, no entanto, équeseu ensaio não apenas desen coraja qualquer discussão, mastenta ativamente impedir o debate produtivo através de gestos de desdém, que são o oposto de um debate intelectual entre pares, político e proveitoso.

23. Se os intelectuais quiserem dominar seus instrumentos analíticos, dizem Bourdieu e W acquant, preci samos de "uma história genuína sobre a gênese das idéias a respeito do mundo social, combinada a uma análi se dos mecansi mos sociais de circulação intelectual dessas idéias" (Bourdieu \& W acquant, 1999:51). O s autores apenas reconhecem a questão do "consumo", para usar o tipo de metáfora mercantilista tão apreciada por eles, em uma referência à "retradução [local] de problemas sociais relevantes" atuais para um vocabulário importado pelos nativos (ibidem:50).

24. Aqueles sem muito contato ou conhecimento da comunidade afro-norte-americana tendem a pensar erroneamente, como notou $\mathrm{H}$ anchard em sua resposta a Peter Fry em 1996, que há apenas um "modo de ser" entre os descendentes de africanos nos EU A. Esta subestimação da diversidadeinterna dentro dosEU A, uma noção equivocada, mas presente em Bourdieu e W acquant, assim como em muitos brasileiros, pode levar a uma interpretação distorcida da forma-de-ser afro-norte-americana como monolítica e implicitamente separatista (Segato, 1998:134, 130). A pesar de escapar facilmente àqueles queestão do lado de fora, o tema da integração e da busca de uma sociedade igualitária racialmente, não são, de maneira alguma, marginais para a vida e luta atuais dos afro-norte-americanos.

25. A crítica de Silva ébem exemplificada pelo argumento deW inant de que sua "teoria da formação racial" é "particularmente ad equada para lidarmos com as complexidades da dinâmica racial brasileira [porque] a raça é vista como constitutiva da psiquê individual edosrelacionamentosentreindivíduos; elaétambém um componenteir- 


\section{John French}

redutível de identidades coletivas e estruturas sociais" (W inant, 1994:94, ênfase minha).

26. Livio Sansone, um brasilianistaitaliano, criticaW inant por defender que "uma polarização étnica global e unilinear esteja ocorrendo, o que basicamente significa postular o desenvolvimento por todo o mundo de um tipo único, polarizado, de relações raciais e racismo - uma cópia em gran de escala da situação nos EU A e, em menor escala, no N ordeste Europeu. Tais general izações refletem uma dificuldade geral dentro dos estudos étnicos em relação a situações de mestizaje com fronteiras étnicas pouco claras e subestima as peculiaridades das relações de raça e identidade étnicas no Brasil [...]. Até mesmo com a globalização", nota com bom senso, "al gumas diferenças básicas continuam a existir entrea cultura eas identidades negras na Bahia ea diáspora negra européia ou a comunidade negra nos Estados U nidos" (Sansone, 1997:303-4).

27. A questão de "idéias fora do lugar" e "importadas" pode ser en contrada na minha recentediscussão dos debatesem torno do extenso, mas problemático, sistema brasil leiro de leis trabal histas (French, 1998; 2001).

28. D evo este argumento aJ an $\mathrm{H}$ offman French, cujas idéias e insi ghts sobre o B rasil al imentam este ensaio.

29. A participação crescente de intelectuais brasileiros de descendência africana é um desdobramento novo em termos da sociologia do conhecimento. A ausência deintelectuais afro-latino-americanos, lamentava Pierre Fontaine em seu artigo de 1980, reflete "a estrutura e distribuição de riqueza, poder e status na região. Fal ando mais diretamente, esta situação reflete o fato de queos latino-americanos, devido à suafalta de riqueza, status e poder, têm tido pouca influência na formação e desenvolvimento" dos Estudos Latino-Americanos (Fontaine, 1980:111).

\section{Referências Bibliográficas}

AN D REW S, G eorge Reid (1998). N egros e Brancos em São Paulo, 1888-1988. Bauru, Editora da U niversidade do Sagrado C oração.

_ (1997). Slavery and Race Relati onsin Brazil. Albuquerque, U niversity of N ew M exiCo.

_ (1992). "D esigualdade Racial no Brasil e nos Estados U nidos: U ma Comparação Estatística”. E studos Afro-Asiáticos, no 22, pp. 47-83.

__ (1991). "Appendix B: Brazilian Racial Terminology". In G. R. Andrews (ed.), Blacks and Whites in São Paulo, Brazil (1888-1988). M adison, U niversity of W isconsin Press, pp. 249-58.

BAIRRO S, Luiza (1996). “O rfeu ePoder: U ma Perspectiva Afro-Americana sobre a Política Racial no Brasil". Afro-Asia, no 17, pp. 173-86.

BARCELOS, Luiz Cláudio; CU N H A, O lívia M . G . da\& ARAÚ JO, T ereza C. N . (eds.) (1991). Escravidão e R elações Raciais no Brasil. C adastro de Produção Intel ectual (1970-1990). Rio de Janeiro, Centro de Estudos Afro-Asiáticos.

BARTHES, Roland (1972). M ythologies. N ew York, H ill and W ang.

BASTIDE, Roger. (1974). "The Present Status of Afro-American Research in Latin America". D aedalus, no 103, pp. 111-123.

\section{6}


Passosem Falso da Razão Antiimperialista...

BLAN C O , M eridaH olderness (1978). Raceand F aceamong the Poor: T he Language of Color in a Brazilian Bairro. Tese de D outoramento em Antropologia, Stanford U niversity.

BO URDIEU, Pierre \& W ACQ UANT, Loïc (1999). "O n the Cunning of Imperialist Reason". Theory, Culture \& Society, vol. 16, no 1, pp. 41-58.

(1998). "Prefácio: Sobre as Artimanhas da Razão Imperialista". In P. Bourdieu, Escritos de Educação. Petrópolis, Editora Vozes, pp.17-32.

BURDICK, John (1998). Blessed Anastácia: Women, Race and Popular Christianity in Brazil. N ew York, Routledge.

BUTLER, Kim D. (1998). Freedoms Given, Freedoms W on: Afro-Brazilians in Post-Abolition São Paulo and Salvador. N ew Brunswick, NJ, Rutgers University Press.

(1996). "Book R eview: O rpheusand Power". TheJ ournal of I nterdisciplinary H istory, vol. 27, no 2, pp. 366-367.

CAET AN O, M iriam E. \& CUN H A, H enrique (1992). "Afro-Brazil: The Black M ovement and Community Education". In C. Poster \& J. Zimmer (eds.), Community Education in the Third World. London, Routledge.

CAV ALCAN TI, M aria Laura V. de C astro (1999). "Preconceito de M arca: Etnografia e Relações Raciais". Tempo Social, vol. 11, no 1, pp. 97-110.

COMAROFF, John \& COM AROFF, Jean (1992). "Of Totemism and Ethnicity". In Ethnographyand theH istorical I magination. Boulder, co, W estview Press, pp. 49-67.

COST A, Emília V. da (1985). The M yth of Racial Democracy: A Legacy. Chicago, The University of Chicago Press, pp. 234-246.

C U N H A, O lívia M . G omes da (1998). “Black M ovements and the 'Politics of I dentity' in Brazil". In S. E. Alvarez, E. D agnino \& A. Escobar (eds.), Cultures of Politics, Politics of Cultures: Revisioning Latin American Social M ovements. Boulder, W estview Press, pp. 220-251.

DEG LER , Carl (1986). N either Black nor W hite: Slaveryand RaceRelationsin B razil and the $U$ nited States. M adison, U niversity of $W$ isconsin Press.

DZIDZIENYO, Anani (1991). “Afro-Brasileiros no Contexto N acional e Internacional". In P. Lovell (ed.), D esigual dadeR acial no Brasil Contemporâneo. Belo H orizonte, U FM G/C edeplar, pp. 51-91.

FER N AN D ES, Florestan (1989). “A Classe M édia e os M ulatos: A Q uestão dos 'N egros de Alma Branca'". In Significado do Protesto N egro. São Paulo, Cortez, pp. 65-76.

FO N T AIN E, Pierre-M ichel. (ed.). (1995). Race, Classand Power in Brazil. LosAngeles, U CLA Center for Afro-American Studies.

_ (1980). "R esearch in the Political Economy of Afro-Latin America". L atin American Research Review, nำ15, pp. 111-42.

FREN CH , John D . (2001a). D a O utorga ao D ireito: A CLT ea Cultura Política dosTrabalhadores. São Paulo, Fundação Perseu Abramo.

(2001b). Sharing the Riches of Afro-Brazilian H istory: U ndergraduateand G raduate $T$ eaching Syllabi and $\mathrm{H}$ andouts. D urham, The African and African-American Studies Program and Latin American and $C$ aribbean Studies $C$ enter of D uke U niversity. 


\section{John French}

(1998). "D rowning in Laws but Starving (for Justice?): Brazilian Labor Law and the W orkers' Q uest to Realize the Imaginary". Political Power and Social Theory, no 12, pp. 177-214.

FREN CH, J ohn D .; M Ö RN ER, M agnus \& VIÑ U ELA, Julia Fawaz. (1982). “Comparative A pproaches to Latin A merican $\mathrm{H}$ istory". Latin American Research Review, vol. 17, no 2, pp. 55-89.

FRY, Peter (1995-96). "O que a C inderela N egra tem a dizer sobrea 'Política Racial' no Brasil". Revista da U SP, no 28, pp. 122-135.

_ (1995). "W hy Brazil is D ifferent" (Book Reviews of the books by Michael $\mathrm{H}$ anchard and J oão J osé Reis). T imes Literary Supplement, no 8, dezembro, pp. 6-7.

FUENTE, Alejandro de la (1995). "Book Review: Orpheus and Power". Hispanic-American Historical Review, no 75, pp. 496-497.

GRAH AM, Richard (1995). "Book Review: O rpheus and Power". American Journal of Sociology, no 100, pp. 1637-39.

GUIM ARÃES, Antonio S. Alfredo (1999). "Baianos ePaulistas: D uas 'Escolas' de Relações Raciais?". Tempo Social, no 11, pp. 75-96.

_ (1995a). "Racism and Anti-Racism in Brazil: A Postmodern Perspective". In B. P. Bowser (ed.), Racism and Anti-Racism in World Perspective. Thousand 0 aks, CA, Sage.

_ (1995b). "Racismo e Anti-Racismo no Brasil". N ovos Estudos C ebrap, no 43, pp. 26-44.

H AN CH ARD , M ichael G. (1996a). " 'Americanos' Brasil leiros e a Cor da Espécie H umana: U ma resposta a Peter Fry". Revista da U SP, no 31, pp. 164-75.

__ (1996b) "Cinderela N egra? Raça e Esfera Pública no Brasil”. Estudos A fro-A siáticos, no 30, pp. 41-59.

_ (1996c). "Resposta a Luiza Bairros". Afro-Asia, o 18, pp. 227-34.

_ (1995). "F azendo a Exceção: $N$ arrativas de I gual dade Racial no Brasil, no M éxico, e em Cuba". Estudos Afro-Asiáticos, no 28, pp. 203-217.

_ (1994a). O rpheus and Power: The M ovi mento N egro of Rio de Janei ro and São Paulo, Brazil, 1945-1988. Princeton, N J, Princeton U niversity Press.

_ (1994b). "Black Cinderella? Race and the Public Sphere in Brazil". Public Culture, oㅜ 7, pp. 165-185.

_ (1993). "Culturalism versus C ultural Politics: M ovimento N egro in Rio de Janeiro and São Paulo, Brazil". In K. W arren (ed.), TheV iolenceW ithin: Cultural and Political 0 pposition in D ivided N ations. Boulder, Westview Press, pp. 57-85.

_ (1991). "Racial C onsciousness and Afro-D iasporic Experiences: Antonio Gramsci Reconsidered". Socialism and Democracy, no 14, pp. 83-106.

H ASEN BALG, C arlos A. (1985). "Race and Socioeconomic Inequalities in Brazil". In P-M . Fontaine (ed.), Race, Class, and Power in Brazil. Los Angeles, U CLA C enter for Afro-American Studies.

_ (1979a). D iscriminação e D esi gualdades Raciais no Brasil. Rio de Janeiro, G raal.

_ (1979b). "Excepcionalidade do Corriqueiro: As N otícias sobreD iscriminação Racial na Imprensa". Revista de Cultura Contemporânea, no 1, pp. 75-88.

\section{8}




\section{Passosem F also da Razão Antiimperialista...}

HELLW IG, D avid J. (ed.) (1992). African-American Reflections on Brazil's Racial Paradise. Philadelphia, PA, Temple U niversity Press.

JOH N SO N, Randal. (1987). "Tupy or not Tupy: Cannibalism and N ationalism in Contemporary Brazilian Literature and Culture." In J. King (ed.), M ordern Latin American Fiction: A Survey. London, Faber and Faber.

LO VELL, Peggy (1994). "Race, G ender, and D evelopment in Brazil". Latin American Research Review, no 27, pp. 7-36.

M ARX, Anthony W. (1998). M aking Race and N ation: A C omparison of South A frica, the U nited States, and Brazil. Cambridge, C ambridge U niversity Press.

M ITCHELL, M ichael (1995). "Book Review: Orpheus and Power". Luso-Brazilian Review, no 32, pp. 2116-118.

N O GUEIRA, O racy (1985). "Preconceito Racial deM arca ePreconceito Racial de O rigem". In O . N ogueira (ed.), Tanto Preto Q uanto B ranco: Estudos de Relações Raciais. São Paulo, T. A. Q ueiroz.

(1959). "Skin Color and Social Class". In Research Institute for the Study of M an, Colombia U niversity \& The Pan American U nion (eds.), Plantation Systems of the $\mathrm{N}$ ew World. W ashington, DC, Pan American U nion.

OLIVEIRA, Lucia Lippi (1995). A Sociologia do Guerreiro. Rio de Janeiro, Editora UFRJ.

PARKER, D orothy B. (ed.). (1978). Afro-Braziliana: A W orking Bibliography. Boston, G. K. H all.

RAEDERS, G eorges (1988). O Inimigo Cordial do Brasil: 0 CondedeG obineau no Brasil. Rio de Janeiro, Paz e Terra.

REICH M AN N , R ebecca (ed.) (1999). Racein Contemporary Brazil: From Indifferenceto Inequality. U niversity Park, Pennsylvania State U niversity Press.

RO UT, LeslieB. (1973). "Sleight of $\mathrm{H}$ and: Brazilian and American Authors M anipulate the Brazilian Racial Situation, 1910-1951". T he Americas, № 29, pp. 471-88.

RU SSELL-W O OD , A. J. R. (1982). Africans and Europeans: H istoriography and Perceptions of Reality". The Black M an in Slavery and Freedom in Colonial Brazil. N ew York, St. M artin's Press, pp. 1-26.

SAN SO N E, Livio (1997). "The N ew Politics of Black Culture in Bahia, Brazil". In C. Govers \& H. Vermeulen (eds.), The Politics of Ethnic C onsci ousness. N ew York, St. M artin's Press, pp. xi, 377.

SAN TIAG O , Silvano (1978). “Entre-Lugar do D iscurso Latino-Americano". U ma Literatura nos T rópicos. São Paulo, Editora Perspectiva, pp. 11-28.

SAN T O S, Joel Rufino dos. (1996). "O N egro C omo L ugar". In M . C . M aio \& R. V. Santos (eds.) , Raça, Ciência eSoci edade. Rio deJaneiro, Editora FioC ruz/C entro Cultural Banco do Brasil, pp. 219-224.

SC W ARZ, Roberto (1992). M isplaced I deas: Essayson Brazilian Culture. London, Verso.

SEG AT O, Rita (1998). "T heC olor-Blind Subject of M yth. O r, W hereto Find Africa in the N ation". Annual Review of Anthropology, no 27, pp. 129-51.

SH ERIFF, Robin E. (1997a). "N egro is a N icknamethat the W hites Gaveto the Blacks": $D$ iscourseson Color, Race and Racism in Rio de Janeiro. T ese dePh.D em Antropologia, City U niversity of N ew York, inédita.

_ (1997b). Tornando-se um N egro Assumido: O D iscurso da Conversão. S/I, s/e. 


\section{John French}

SILVA, D enise F. da (1998). "Facts of Blackness: B razil isnot (Q uite) theU nited States... and Racial Politics in Brazil?". Social Identities, vol. 4, no 2, pp. 201-234.

SILVA, N elson do V alle (1985). "Updating the Cost of $\mathrm{N}$ ot Being W hite in Brazil". In P.-M . Fontaine (ed.), Race, Class, and Power in Brazil. Los Angeles, U C LA Center for Afro-American Studies.

SKID M O RE, Thomas E. (1993). "Bi-racial U SA vs. M ulti-racial Brazil: I sthe Contrast Still Valid?". J ournal of Latin American Studies, no 25, pp. 373-86.

__ (1992). "EU A Bi-Racial vs. Brasil M ulti-Racial: 0 Contraste ainda éV álido?". N ovos Estudos Cebrap, ํㅡ 34, pp. 49-62.

TELLES, Edward E. (1994). "Industrialization and Racial Inequality in Employment: The Brazilian Example". American Sociological Review, no 59, pp. 46-63.

_ (1993). "Racial Distance and Region in Brazil: Intermarriage by Color in Brazilian U rban Areas". Latin American Research Review, vol. 28, no 2, pp. 141-62.

_ (1992). "Segregation by Skin Color in Brazil". American Sociological Review, № 57, pp. 186-97.

TWIN E, France W inddance (1997). Racism in a Racial D emocracy: The M aintenance of White Supremacy in Brazil. N ew Brunswick, N J, Rutgers U niversity Press.

W AGLEY, Charles (1959). "O $n$ the Concept of Social Race in the Americas". Actasdel XXXIII Congreso Internacional de Americani stas, no 1, pp. 403-7.

W IN AN T, H oward (1996). "Book Review: O rpheusand Power". J ournal of Latin American Studies, no 28, pp. 248-49.

__ (1994). Racial Conditions: Politics, Theory, Comparisons. M inneapolis, U niversity of $M$ innesota Press.

W O OD, C harles H \& \& CARVALH O, José Alberto de M . (1988). The D emography of Inequality in Brazil. Cambridge, Cambridge U niversity Press. 